\title{
EL GÉNERO PASPALUM L. (PASPALEAE, POACEAE) EN LA PENÍNSULA DE YUCATÁN, MÉXICO
}

\author{
Juan Javier Ortiz-Díaz ${ }^{1,5}$, Itziar Arnelas ${ }^{2}$, Rosa Cerros-Tlatilpa ${ }^{3}$, María Elena \\ Siqueiros-Delgado ${ }^{4}$ y Juan Tun-Garrido ${ }^{1}$
}

${ }^{1}$ Universidad Autónoma de Yucatán, Campus de Ciencias Biológicas y Agropecuarias, Apdo. postal 4-116, Mérida, Yucatán, México. ${ }^{2}$ Herbario HUTPL, Departamento de Ciencias Naturales, Universidad Técnica

Particular de Loja, Apartado postal 11-01-608, Ecuador. ${ }^{3}$ Universidad Autónoma de Morelos, Avenida Universidad 1001, Colonia Chamilpa, 62210 Cuernavaca, Morelos, México.

${ }^{4}$ Universidad Autónoma de Aguascalientes, Avenida Universidad 940, 20000 Aguascalientes, Aguascalientes, México.

5 Autor para la correspondencia: odiaz@uady.mx

\section{RESUMEN}

En este estudio se llevó a cabo una sinopsis del género Paspalum L. en la Península de Yucatán, México. Se reconocen 23 especies en el área de estudio, se proporcionan claves de identificación, descripciones morfológicas, mapas de distribución, así como información acerca de su fenología, hábitat y distribución. Se reconocen dos especies endémicas de la Península de Yucatán, P. mayanum y P. sparsum, localizadas en áreas abiertas de la selva baja caducifolia.

Palabras clave: Campeche, clave de identificación, endemismo, gramíneas, Quintana Roo, taxonomía, Yucatán.

\section{ABSTRACT}

In this study, a synopsis of Paspalum L. was performed in the Yucatan Peninsula, Mexico. Twenty-three taxa are recognized in the study area, identification keys are provided, as well as morphological descriptions, distribution maps, habitat, phenology and distribution data. Two endemic species are recognized for the Yucatan Peninsula, P. mayanum and P. sparsum, which are found in open areas of tropical deciduous forest. 
Key words: Campeche, identification key, endemism, grasses, Quintana Roo, taxonomy, Yucatán.

\section{INTRODUCCIÓN}

El género Paspalum L. es miembro de la tribu Paspaleae de la familia Poaceae. De acuerdo con estudios filogenéticos recientes (Morrone et al., 2012), es uno de los más diversos dentro de la familia Poaceae, con alrededor de 350 especies ( $\mathrm{Zu}$ loaga y Morrone, 2005), confinadas a las regiones tropicales y templadas de ambos hemisferios, en especial del hemisferio oeste, siendo particularmente bien representado en los Cerrados de Brasil (Chase, 1929; Hitchcock, 1971). Paspalum comprende especies de mayor importancia económica, ya que un gran número de ellas proveen un excelente pasto, como P. dilatatum y P. notatum. Paspalum vaginatum es un buen inmovilizador del suelo en costas arenosas en los trópicos y subtrópicos y P. distichum es usado para proteger suelos de la erosión, por citar algunos casos (Zuloaga y Morrone, 2005). Asimismo, se han registrado especies que ocasionan graves problemas, como por ejemplo la obstrucción de canales de drenaje debido a la presencia de $P$. repens (Chase, 1929).

Morfológicamente las plantas de Paspalum se caracterizan por presentar espiguillas biflosculares plano convexas, siendo ésta probablemente la única sinapomorfia del género (Rua et al., 2010). Además, las espiguillas generalmente carecen de la primera gluma y la lema fértil presenta los márgenes enrollados (Chase, 1929; Hitchcock, 1971). Han sido numerosos los trabajos encaminados a esclarecer la clasificación infragenérica de Paspalum (Döll, 1877; Nash, 1912; Chase, 1929; Pilger, 1929; Zuloaga, 1974; Clayton y Renvoize, 1986; Cialdella et al., 1995; Denham et al., 2002; Morrone et al., 1995, 1996, 2000, 2004; Rodríguez, 1992, 1998; Zuloaga y Morrone, 2003, 2005; Zuloaga et al., 2004; Denham, 2005; Denham et al., 2010). Sin embargo, no existe un esquema natural de clasificación dentro del mismo (Rua et al., 2010), ya que dichas propuestas se basan en macrocaracteres morfológicos que se presentan en grupos de especies aparentemente poco relacionadas (Zuloaga y Morrone, 2005). En el presente trabajo, acorde con los trabajos de Zuloaga et al. (2004), Zuloaga y Morrone (2005), Denham (2005) y Denham et al. (2010), basados en los estudios previos de Nash (1912) y Chase (1929), se reconocen cuatro subgéneros: subg. Anachyris Chase, subg. Ceresia (Pers.) Rechb., subg. Harpostachys (Trin.) S. Denham y subg. Paspalum, este último con un total de 40 grupos informales. 
En México, Paspalum es el género más diverso de la subfamilia Panicoideae con 85-88 especies (Zuloaga y Morrone, 2003; Dávila et al., 2006; Sánchez-Ken, 2010). En la Península de Yucatán se registran 23 especies (Ortiz-Díaz y Flores Guido, 2008; Carnevali et al., 2010), y aunque esta cantidad ha variado de 14 a 21 en trabajos taxonómicos previos de Paspalum en la región (Swallen, 1934; Pohl y Davidse, 1994), sigue siendo el género más diverso de la familia Poaceae en la región. El gran número de especies presentes en la Península de Yucatán está en relación con la diversidad de comunidades vegetales y ambientes tropicales en las que se prospera, encontrándose en selvas, sabanas, manglares y dunas costeras, en sitios abiertos secos o inundados.

En virtud de que Paspalum es el género más diversificado de la familia Poaceae en la Península de Yucatán y contiene especies ecológicamente importantes como P. plicatulum y P. coryphaeum, se hace necesario actualizar y ampliar la información taxonómica, ecológica y distribución geográfica en el territorio de estudio.

\section{MATERIAL Y MÉTODOS}

El estudio se basó en la revisión de especímenes colectados en campo por el primer autor y en el acervo conservado en los herbarios CICY, F, ITIC, MEXU, MO, UADY, UCAM, US, WIS y XAL. Para la determinación de los ejemplares y para las descripciones se consultaron los trabajos de Chase (1929), Swallen (1934), Pohl y Davidse (1994), Allen y Hall (2003), Zuloaga et al. (2004), Zuloaga y Morrone (2005), Denham (2005) y Denham et al. (2010). Se proporcionan claves para la identificación de los subgéneros y especies. En la sinonimia de las especies, solamente se han considerado aquellos nombres cuyos tipos proceden de México. La información para la distribución de los taxa se ha obtenido de Pohl y Davidse (1994), Dávila et al. (2006), Allen y Hall (2003), Sánchez-Ken (2010), Soreng et al. (2014), y World Checklist of Selected Plant Families (WCSP, 2014). Se elaboraron mapas de distribución geográfica y se proporciona información sobre la fenología, hábitat y distribución para todos los taxones de la Península de Yucatán.

\section{RESULTADOS}

El género Paspalum está representado en la Península de Yucatán por 23 especies. El subgénero Anachyris lo está por P. malacophyllum; Harpostachys por $P$. 
botterii, y el subgénero Paspalum por las 21 especies restantes correspondientes a 14 grupos informales (grupo Caespitosa: P. blodgettii, P. caespitosum; Conjugata: P. conjugatum; Corcovadensia: P. corcovadense; Dissecta: P. repens; Disticha: P. vaginatum; Fasciculata: P. fasciculatum; Fimbriata: P. fimbriatum; Livida: P. alcalinum; Notata: P. notatum var. notatum; Parviflora: P. clavuliferum; Paniculata: P. mayanum, $P$. paniculatum, P. sparsum; Plicatula: P. ligulare, P. plicatulum, $P$. wrightii; Quadrifaria: P. coryphaeum; Virgata: P. arundinaceum, P. millegrana, P. virgatum). En este estudio el subgénero Ceresia no se encuentra representado por ninguna especie.

Paspalum L., Syst. Nat., ed. 10, 2: 855. 1759. TIPO (lectotipo designado por Chase, Proc. Biol. Soc. Wash. 24: 137. 1911): Paspalum dimidiatum L., nom. illeg. superfl. = Paspalum dissectum (L.) L.

= Ceresia Pers., Syn. Pl. 1: 85. 1805. TIPO: C. elegans Pers.

= Reimaria Flüggé, Gram. Monogr., Paspalum: 213. 1810. TIPO: R. candida Flüggé. = Thrasya Kunth., Nov. Gen. Sp. 1: 120-121. 1815 (1816). TIPO: T. paspaloides Kunth. = Paspalanthium Desv., Opusc. Sci. Phys. Nat. 59. 1831. TIPO: P. stoloniferum (Bosc) Desv.

= Anachyris Nees, Hooker's J. Bot., Kew Gard. Misc. 2: 103. 1850. TIPO: A. paspaloides Nees.

= Dimorphostachys E. Fourn., Compt. Rend. Hebd. Séances Acad. Sci. 80: 441. 1875. TIPO: D. monostachya (Kunth) E. Fournet.

= Tylothrasya Döll, Fl. Bras. 2: 295. 1877. TIPO: T. petrosa (Trin.) Döll.

Hierbas anuales o perennes, cespitosas, estoloníferas o rizomatosas. Culmos generalmente erectos, otras veces decumbentes, rastreros o flotantes enraizados, a veces geniculados, simples o ramificados, glabros. Hojas con vainas abiertas, aurículas a veces presentes; lígula membranosa, glabra o ciliada con pelos unicelulares; lámina plana, raramente convoluta. Sinflorescencia formada por racimos insertos en un raquis filiforme o alado, $1 \mathrm{o}$ varios, axilares $\mathrm{y} / \mathrm{o}$ terminales, 1 a numerosos, a veces los racimos se desprenden como una unidad, glabros o pelosos en el punto de inserción. Espiguillas cortamente pedunculadas, comprimidas dorsalmente, dorso de la espiguilla orientada hacia el raquis, solitarias o pareadas, dispuestas en 2-4 filas, cortamente pediceladas o sésiles, generalmente naviculares, plano-convexas o cóncavo convexas, obtusas, agudas o subagudas, a veces apiculadas, desarticulación por debajo de la gluma, la espiguilla caediza como una unidad, en algunas especies la espiguilla del par es reducida; glumas desiguales, la inferior generalmente ausen- 
te, raramente presente y reducida a una escama membranosa deltoide o triangular, frecuentemente excéntrica; gluma superior generalmente casi tan larga como la espiguilla o un poco más corta que ella, rara vez ausente o reducida, membranácea, generalmente con 3-5 nervios, con dorso convexo. Dos flósculos, el inferior generalmente estéril, con lema membranosa, sin o raramente con una palea hialina salvo los nervios endurecidos, a veces estaminado; el superior bisexual, hialino, membranáceo, cartáceo, coriáceo o crustáceo, agudo a redondeado, glabro; lema inferior generalmente similar a la gluma superior; lema superior lisa o estriada, convexa, los márgenes enrollados o no sobre las orillas de la palea, de color blanquecino o amarillo pálido a pardo, u opaca o brillante; pálea superior aplanada; lodículas 2, estambres 3, estilos 2. Fruto una cariópside ampliamente elíptica o circular, plano convexa o plana, blanca, pálida, amarilla pálida o parda.

Clave para la determinación de los subgéneros de Paspalum

1a Espiguillas naviculares; gluma superior generalmente ausente; lema superior sulcada por 5 nervios prominentes ... P. subg. Anachyris Chase (P. malacophyllum) 1b Espiguillas plano-convexas o cóncavo-convexas, no naviculares; gluma superior usualmente presente; lema superior lisa, con nervios indistinguibles ............... 2

2a Gluma inferior usualmente presente y dimorfa en las espiguillas de un par; pálea inferior reducida o ausente; hojas distales con sinflorescencias axilares P. subg. Harpostachys (Trin.) S. Denham (P. botterii)

$2 \mathrm{~b}$ Gluma inferior generalmente ausente, cuando presente isomorfa en todas las espiguillas de un par; pálea inferior generalmente ausente; hojas distales con sinflorescencias terminales P. subg. Paspalum

\section{Paspalum subg. Paspalum}

Clave para la determinación de especies del subgénero Paspalum

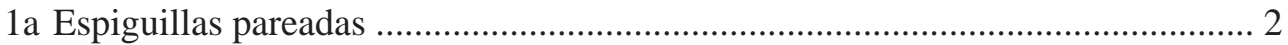

1b Espiguillas solitarias, raramente pareadas en P. corcovadense ......................... 17

2a Espiguillas de $1.3 \mathrm{~mm}$ o menos de ancho ............................................................ 3

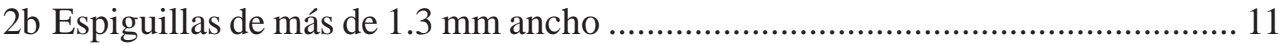

3a Sinflorescencia con más de 18 racimos .......................................... P. paniculatum 


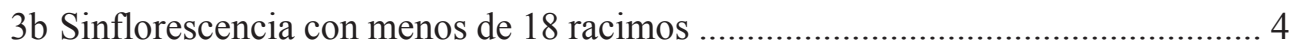

4a Plantas anuales; sinflorescencia con 1-2 racimos, conjugados cuando 2

P. clavuliferum

4b Plantas perennes; sinflorescencia con 2-12 racimos, no conjugados cuando 2 .... 5

5a Espiguillas de 1-1.3 mm de largo; gluma superior densamente glandular-puberulenta P. blodgettii

5 b Espiguillas de más de $1.3 \mathrm{~mm}$ de largo; gluma superior diferente 6

6a Espiguillas de 2.5-2.8 mm de largo; raquis 1-1.1 mm de ancho; flósculo superior pardo, brillante P. wrightii

$6 \mathrm{~b}$ Espiguillas de 1.2-2.5 mm de largo; raquis 0.3-0.8 $\mathrm{mm}$ de ancho; flósculo superior amarillo pálido o blanquecino, no brillante 7

7a Espiguillas con indumento lanoso P. sparsum

$7 \mathrm{~b}$ Espiguillas con indumento adpreso-peloso o glabras 8

8a Espiguillas 1.5-1.8 × 0.8-0.9 mm, obovadas; hojas velutinas P. mayanum

8b Espiguillas 1.6-2.5 × 0.8-1.3 mm de largo, elípticas; hojas glabrescentes o esparcidamente pelosas

9a Sinflorescencia con 12-14 racimos de 4-12 cm largo, patentes o péndulos; láminas foliares $10-20 \mathrm{~mm}$ de ancho P. coryphaeum

9b Sinflorescencia con 2-8 racimos de 1.5-9 cm de largo, ascendentes o divergentes; láminas foliares 4-15 $\mathrm{mm}$ de ancho 10

10a Lígula 0.5-0.6 mm de largo; sinflorescencias con racimos de 1.5-4 cm largo; espiguillas 1.6-2 mm largo P. caespitosum

10b Lígula 0.7-2.5 mm de largo; sinflorescencias con racimos de 4-9 cm largo; espiguillas 2-2.5 mm largo P. corcovadense

11a Márgenes de la gluma superior alados, cartilaginosos, fimbriados

11b Márgenes de la gluma superior diferentes ....................................................... 12

12a Flósculo superior blanquecino o amarillo pálido ............................................ 13

12b Flósculo superior pardo o pardo obscuro, opaco o brillante ............................. 16

13a Espiguillas suborbiculares ..................................................... P. millegrana

13b Espiguillas obovadas, elípticas o elíptico-obovadas .................................... 14

14a Espiguillas elípticas, dos veces más largas que anchas; gluma superior homogéneamente pelosa, aguda ............................................................... P. alcalinum

14b Espiguillas obovadas o elíptico-obovadas, 1-1.6 veces más largas que anchas; gluma superior glabrescente, obtusa ............................................................ 15

15a Sinflorescencia con 4-6 racimos ................................................... P. ligulare

15b Sinflorescencia con 10-20 racimos ........................................ P. arundinaceum 
16a Flósculo superior pardo, no brillante; plantas robustas, culmo generalmente más de 100 cm de largo; lema no corrugada transversalmente sobre los márgenes ..... P. virgatum

16b Flósculo superior pardo obscuro, brillante; plantas no robustas, culmo menor de $100 \mathrm{~cm}$ de largo; lema corrugada transversalmente hacia los márgenes

P. plicatulum

17a Plantas acuáticas, frecuentemente flotantes; vainas infladas P. repens

17b Plantas terrestres, nunca flotantes; vainas no infladas 18

18a Sinflorescencias con 14-25 racimos, flabeliformes P. fasciculatum

18b Sinflorescencias con 2-3(-4) racimos, no flabeliformes 19

19a Sinflorescencias con 2-3 racimos, no conjugados cuando 2 ...... P. corcovadense 19b Sinflorescencias con 2(-4) racimos, conjugados cuando 2 20

20b Espiguillas de 1.3-1.7 mm de largo; la gluma superior papiloso-ciliada

P. conjugatum

20a Espiguillas de 3.2-4 mm de largo; la gluma superior glabra 21

21a Espiguillas 1.2-1.5 mm de ancho, agudas P. vaginatum 21b Espiguillas 2.3-2.8 mm de ancho, obtusas P. notatum var. notatum

Paspalum alcalinum Mez, Repert. Spec. Nov. Regni Veg. 15: 75. 1917, nom. cons. prop. P. buckleyanum 1803, Taxon 57(1): 304. 2008. TIPO: MÉXICO. San Luis Potosí: Hacienda de Angostura, Jul., C. G. Pringle 3764 (holotipo, B; isotipos, B, MA181652, MEXU, MO, P00741007, US, US, W) (Fig. 1A).

Ic. Denham, S. S. et al. Ann. Missouri Bot. Gard. 97(1): 14. 2010.

Perennes cespitosas, con rizomas cortos y estolones. Culmos erectos, ramificados desde la base, 30-90(-120) cm alto; entrenudos glabros, nudos más o menos pilosos. Hojas con vainas carinadas, glabras a pilosas o papiloso-pelosas; lígula 2-3 mm largo; láminas 10-30 cm largo, 3-6 mm ancho, lineares, aplanadas a convolutas, pilosas en la garganta, márgenes escábridos. Sinflorescencia 7-16 cm largo, con 4-12 racimos de 4-7 cm largo, ascendentes, adpresos o poco divergentes, laxos; raquis 1.2-1.6 mm de ancho, cortamente escabroso, con una espiguilla en el ápice, aplanado. Espiguillas 2.5-3 mm largo, 1.2-1.5 mm ancho, elípticas, pareadas, en 4 filas; gluma inferior ausente; gluma superior y lema inferior tan largas como la espiguilla, gluma superior homogéneamente pelosa, aguda, apiculada, con 5 nervios, lema inferior homogéneamente pelosa o glabrescente, aguda, apiculada, con 3 nervios, los laterales submarginales. Flósculo superior 2.5-3 mm largo, fuertemente papiloso, estriado, amarillo pálido. 
Esta especie florece de julio a septiembre. Habita praderas húmedas, zanjas de caminos en sustrato alcalino, en altitudes próximas a nivel del mar. En el área de estudio solamente se ha colectado en Yucatán. En México se le registra también de San Luis Potosí. Esta especie se conoce de Estados Unidos de América (Texas), México y Sudamérica (Argentina, Colombia y Paraguay).

Ejemplares examinados: Yucatán: Municipio Progreso. Progreso, entre 11 y 15 Ago 1932, Swallen 2964 (MEXU, US); Progreso, in ponds south of cienaga, Jul 1938, Lundell y Lundell 8126 (MO). (Fig. 2A).

Observaciones. Paspalum hartwegianum es morfológicamente afín a Paspalum alcalinum y esto ha causado que los materiales citados para la Península de Yucatán hayan sido determinados bajo el primer nombre en los trabajos de Pohl y Davidse (1994), Beetle et al. (1999) y Sánchez-Ken (2010). De acuerdo con Denham et al. (2010), ambas especies se diferencian porque en $P$. hartwegianum las espiguillas son anchamente elipsoides a obovoides y la pilosidad en la gluma superior y lema inferior no es homogénea, siendo más densa hacia los márgenes, con pelos más largos que en el resto de la superficie; también los nervios submarginales de la lema superior son más delicados que en $P$. alcalinum. En relación a los especímenes citados para la región, éstos se han redeterminado como $P$. alcalinum.

Paspalum arundinaceum Poir., Encycl., Suppl. 4: 310. 1816. TIPO: GUAYANA FRANCESA. Sin localidad, M. Martin s.n. (FI).

Ic. Hitchcock, A. S., Manual of the grasses of the West Indies: 233. 1936.

Perennes cespitosas. Culmos erectos, simples, $100-200 \mathrm{~cm}$ alto; entrenudos y nudos glabros. Hojas con vainas comprimidas lateralmente, glabras; lígula 2.5-4 mm largo; láminas $80 \mathrm{~cm}$ largo, 5-10 mm ancho, lineares, rígidas, plegadas cerca de la base, por lo demás aplanadas, escábridas, márgenes escabrosos. Sinflorescencia hasta $25 \mathrm{~cm}$ largo con 10-20 racimos de 5-11 cm largo, ascendentes y patentes, laxos; raquis 0.5-1 mm ancho, angosto, escabroso, con la espiguilla en el ápice, triquetro. Espiguillas 2.2-2.8 $\mathrm{mm}$ largo, $1.8 \mathrm{~mm}$ ancho, obovadas, pareadas, en 4 filas; gluma inferior ausente; gluma superior y lema inferior tan largas como la espiguilla, glabras, obtusas, gluma apiculada, con 3 nervios. Flósculo superior $2 \mathrm{~mm}$ largo, papiloso-estriado, amarillo pálido.

Esta especie florece entre julio y agosto. Se localiza en áreas abiertas pantanosas y sabanas, entre 1-50 m de altitud. En el territorio estudiado hasta la fecha solamente se ha detectado su existencia en Quintana Roo, en altitudes cercanas a 
nivel del mar. Ha sido citada para Campeche por Beetle et al. (1999); sin embargo, no se ha podido localizar el material estudiado por estos autores para tal especie. En México también se la conoce del estado de Veracruz. Se distribuye en Estados Unidos de América, México, Mesoamérica (Belice, Costa Rica, Guatemala, Honduras y Nicaragua), Sudamérica (Brasil, Colombia, Guyana Francesa, Uruguay, Venezuela) y las Antillas (Bahamas, Islas de Barlovento, Caimán, Cuba, República Dominicana, Haití, Jamaica, Puerto Rico, Trinidad y Tobago).

Ejemplares examinados: Quintana Roo: Municipio Othón P. Blanco. Chetumal, carretera Chetumal - Escárcega, sobre brecha al Ingenio Álvaro Obregón, 5 Jul 1980, Téllez y Cabrera 2627 (MEXU, MO) (Fig. 2A).

Paspalum blodgettii Chapm., Fl. South. U.S. 571. 1860. TIPO: ESTADOS UNIDOS DE AMÉRICA. Sin localidad, Blodgett s.n. (Fig. 1B).

= Paspalum yucatanum Chase, Contr. U.S. Natl. Herb. 28(1): 121, f. 71. 1929. TIPO: MÉXICO. Yucatán, Mérida, 11 Jul 1865, A. Schott 597 (holotipo, US-951629).

Ic. Allen, C. M. y D. W. Hall. 2003. Paspalum L. In: Flora of North America Editorial Committee, eds. 1993+. Flora of North America North of Mexico 16+ vols. New York and Oxford. 25(2): 578.

Perennes cespitosas, bases abultadas y escamosas. Culmos erectos, simples, 30-120 cm alto; entrenudos glabros; nudos glabros o pilosos. Hojas con vainas comprimidas longitudinalmente, glabras a pilosas; lígula 0.3-0.5 mm largo; láminas 4-20 cm largo, 3-17 mm ancho, lineares, aplanadas, glabras a pilosas, márgenes escabrosos y papilosos-ciliados. Sinflorescencia 3-14 cm largo con (2)3-12 racimos de 2-8 cm largo, ascendentes a patentes, laxos; raquis 0.6-0.7 $\mathrm{mm}$ de ancho, angosto, escabroso marginalmente, con una espiguilla en el ápice, triquetro. Espiguillas 1-1.3 $\mathrm{mm}$ largo, 0.9-1.2 mm ancho, obovadas, pareadas, en 4 filas; gluma inferior ausente; gluma superior y lema inferior tan largas como la espiguilla, gluma superior densamente glandular-puberulenta, obtusa, con 5 nervios; lema glabra a esparcidamente glandular-puberulenta, obtusa, con 2-3 nervios. Flósculo superior 1-1.3 mm largo, liso, amarillo pálido.

Esta especie florece de junio a agosto. En el territorio estudiado se localiza en playas, lados de caminos, campos abiertos con vegetación arbustiva derivada de selva baja caducifolia, selva mediana subcaducifolia y selva baja inundable, en suelos arenoso pedregosos, entre los 5-260 m de altitud. En México solo se le conoce del territorio estudiado: Campeche, Quintana Roo y Yucatán. Su área de distribución abarca 
Estados Unidos de América (Florida), México (Península de Yucatán), Mesoamérica (Belice, Guatemala, Honduras y Panamá) y las Antillas (Bahamas, Islas de Barlovento, Islas Caymán, Cuba, República Dominicana, Haití, Jamaica, Puerto Rico).

Ejemplares examinados: Campeche: Municipio Calakmul. Ejido Bel-Ha, Ak'alché, 8 Nov 1990, Ortega y Ortiz 922 (UADY); $20 \mathrm{~km}$ al S de la entrada de Calakmul, 16 Jul 1997, Martínez et al. 27792 (MEXU, MO); Calakmul, $500 \mathrm{~m}$ al N del poblado, 10 Oct 1997, Martínez et al. 28563 (MEXU); $9 \mathrm{~km}$ al E de Dos Naciones, camino a El Civalito, 29 Jul 1997, Martínez et al. 27850 (MEXU, MO); $10 \mathrm{~km}$ al SE de Dos Naciones, camino a El Civalito, 23 Oct 1997, Martínez et al. 29315 (MEXU, MO); $10 \mathrm{~km}$ al SE de Ley de Fomento Agropecuario, camino a Dos Naciones, 23 Oct 1997, Martínez et al. 29168 (MEXU); carretera Dzibalchen - Xpujil - nuevo Becal Xpujil, 12 Mar 1990, Ortiz 1421 (UADY); Mina de Yeso Coconal, a $23 \mathrm{~km}$ al W de Xpujil, camino a Escárcega, 8 Ago 1997, Martínez et al. 28420 (MEXU, MO); $6.5 \mathrm{~km}$ al E de Flores Magón, 24 Oct 2002, Álvarez 2255 (UCAM); 1 km al W de G. E. Castellot, carretera Xpujil - Escárcega, 21 Sep 2002, Álvarez 2087, (UCAM); 1 km al W de Plan de San Luis, sobre la carretera Escárcega - Chetumal km 134, 26 Nov 1997, Lira et al. 650 (MEXU, MO); $13 \mathrm{~km}$ al S de Xcan-ha, camino a Xpujil, 11 Oct 1997, Martínez et al. 28721 (MEXU, MO); Xpujil, zona arqueológica del río Bec, 13 Jul 1991, Ortega et al. 1702 (UADY); 16 km al NE de Zoh-Laguna, 4 Ago 1997, Martínez et al. 28047 (MEXU, MO). Municipio Calkiní. Hacienda Santa Cruz-Santa María Acú, 19 Sep 2003, Ortiz y Magaña 2212 (UADY); Tankuché - El Remate, entre San Nicolás y Tankuché, 22 Sep 2003, Ortiz 2243 (UADY). Municipio Campeche. Chiná, INIFAP, 14-15 Oct 2008, Carvajal 6, 14 (UADY); carretera Chiná - Uayamon, 26 Sep 1984, Ortiz 634 (CICY); 2 km al O de San Francisco Kobén, 19 Mar 2012, Gutiérrez 10655 (UCAM). Municipio Carmen. Carretera Puerto Real - Ciudad del Carmen, a $10 \mathrm{~km}$ de la ciudad, 20 Oct 1982, Ortiz s.n. (CICY). Municipio Champotón. Camino a Calakmul en el km 20, 11 May 1995, Zamora y Hernández 4279 (UCAM). Municipio Tenabo. 16 km entre Tenabo y Bakú, 28 Ene 1998, Gutiérrez 5665 (UCAM). Quintana Roo: Municipio Benito Juárez. A 1 km NW a Puerto Morelos, Campo Agropecuario del Centro de Investigaciones de Quintana Roo, 24 May 1982, Davidse et al. 20027 (MO); 3 km O de Puerto Morelos en la carretera a Vallarta, 5 May 1982, Davidse et al. 20060 (MO). Municipio Chetumal. 6.5-7 km de Tomás Garrido, 15 Mar 1990, Sanders et al. 9927 (UADY). Municipio Cozumel. Isla de Cozumel, 28 Ago 1982, Flores et al. s.n. (CICY, XAL). Municipio Felipe Carrillo Puerto. Laguna Muyil, $1 \mathrm{~km}$ E of Ruinas Chunyaxché y $26 \mathrm{~km}$ al SO de Tulum, 19 May 1982, Davidse et al. 20640 (MO); a 6 km del pueblo Felipe Carrillo Puerto, camino Vigía Chico, 5 Dic 2001, Simá et al. 2612 (CICY, XAL). Municipio José María Morelos. La Presumida, 
al oeste de la Laguna de Chichancanab, Balneario de Chichancanab, 18 May 1982, Davidse et al. 20608 (MO); $3 \mathrm{~km}$ al N de San José de la Montaña, en la carretera a Tomás Garrido, 9 May 1982, Davidse et al. 20272 (MO). Municipio Lázaro de Cárdenas. Ejido Vicente Guerrero, 8 Jul 1982, Ortiz 228 (CICY, XAL). Municipio Othón P. Blanco. Isla Cayo Lobos, parte sur del Banco Chinchorro, 7 May 1982, Ucan et al. 2055 (CICY). Municipio Solidaridad. Zona arqueológica Muyil, 7 Jul 1983, Durán y Olmsted 302 (CICY, XAL). Yucatán: Municipio Celestún. Carretera Chunchucmil km 3.4, al entronque de la carr. Mérida - Celestún, 29 Nov 2001, Ortiz y Magaña 2111 (CICY). Municipio Chicxulub Pueblo. A 3 km de Chicxulub Puerto, 23 Feb 1984, Ortiz 426 (CICY, XAL). Municipio Dzemul. A 15 km N of Dzemul, 28 Oct 1984, Davidse y Davidse 29464 (MO). Municipio Dzilam de Bravo. N del rancho San Pedro III, 5 Jul 1991, Tun 283 (UADY). Municipio Hunucmá. Reserva Estatal El Palmar, 26 Febrero 2007, Ortiz et al., 2635, 2642(UADY); Sisal hacia el O, Reserva el Palmar, camino de duna costera, 27 Jun 2008, Ortiz 2853 (UADY). Municipio Ixil. A 15 km al O de Telchac, camino terracería a Progreso - San Benito, 23 Jul 1981, Espejel et al. 237 (CICY). Municipio Izamal. Izamal, 1895, Gaumer 852 (F, MO, WIS). Municipio Mérida. Zona arqueológica de Dzibilchaltún, 19 Ene 1984, Ortiz 420 (CICY, XAL). Municipio Oxkutzcab. Carretera Oxkutzcab - Loltun, $2 \mathrm{~km}$ antes de las grutas, 20 Julio 1983, Ortiz 267 (CICY, XAL). Municipio Panabá. Km 14.5 desvío hacia O, rumbo a unión ganadera San Felipe, 26 Feb 2007, Ortiz et al. 2685 (UADY). Municipio Tizimín. Camino El Cuyo - Punta Caracol, 19 Oct 1984, Ortiz 704 (CICY). Municipio Valladolid. $3 \mathrm{~km}$ antes de Valladolid, carretera Valladolid - Pixoy, 16 Ago 1983, Ortiz 300 (CICY). Municipio Yaxcabá. Tixcacaltuyub, 1 Jul 1981, Vargas y Sima 468 (CICY, XAL) (Fig. 2A).

Paspalum caespitosum Flüggé, Gram. Monogr. Paspalum 161. 1810. SINTIPOS: REPÚBLICA DOMINICANA. Insula Hispaniola, P. A. Poiteau et P. J. F. Turpin (BM, P, US-2854139 (fragm. ex BM)); GUYANA. Essequibo, Domina van der Moer. (Herbar. Mertens.). "Specimina mecum communicaverunt Poiteau et Willdenow" (LE, US-951088). La colecta procedente de Essequibo probablemente no pertenece a la colección tipo según Chase (1929). (Fig. 1C).

Ic. Allen, C. M. y D. W. Hall. 2003. Paspalum L. In: Flora of North America Editorial Committee, eds. 1993+. Flora of North America North of Mexico 16+ vols. New York and Oxford. Vol. 25(2): 595.

Perennes densamente cespitosas. Culmos erectos, simples, 35-100 cm alto; entrenudos glabros; nudos más o menos pilosos. Hojas con vainas comprimidas late- 
ralmente, glabras; lígula 0.5-0.6 mm largo; láminas 15-25 cm largo, 4-10 mm ancho, lineares, aplanadas a involutas, casi glabras a pilosas, márgenes escabriúsculos. Sinflorescencia 7-12 cm largo con 3-8 racimos de 1.5-4 cm largo, ascendentes, laxos; raquis 0.4-0.5 mm ancho, angosto, glabrescente, con una espiguilla en el ápice, triquetro. Espiguillas 1.6-2 mm largo, 0.8-1.3 mm ancho, elípticas, pareadas, en 4 filas; gluma inferior ausente; gluma superior escasamente más corta que la espiguilla, casi glabra a esparcidamente adpreso-pelosa, obtusa, con 3-5 nervios; lema inferior tan larga como la espiguilla, glabra, obtusa con 3 nervios. Flósculo superior 1.7-2 mm largo, liso, amarillo pálido.

Esta especie florece de junio a agosto. Crece en herbazales en selva baja caducifolia y selva baja inundable temporalmente, entre los 5-270 m de altitud. En el territorio estudiado se ha localizado en Campeche, Yucatán y Quintana Roo. En México se la conoce también de Chiapas, Puebla, Tabasco, Tamaulipas y Veracruz. Se distribuye en Estados Unidos de América (Alabama, Florida, Hawai), sur de México, Mesoamérica (Belice, Guatemala y Honduras) a las Antillas (Bahamas, Islas Barlovento, Bermudas, Islas Caimán, Cuba, República Dominicana, Jamaica, Puerto Rico).

Ejemplares examinados: Campeche: Municipio Calakmul. Entre ruinas Becán y Chicanná, carretera a Chetumal, 13 May 1995, Zamora et al. 4387 (CICY); a $20 \mathrm{~km}$ al S de la caseta de vigilancia de la Reserva de la Biosfera de Calakmul, 24 Nov 1997, Lira et al. 457 (MEXU, MO); a $37 \mathrm{~km}$ al S de la Caseta de entrada a Calakmul, 8 Ago 1997, Martínez et al. 28161 (MEXU, MO); a $34 \mathrm{~km}$ al S de la caseta de entrada a Calakmul, 16 Oct 1997, Martínez et al. 28951 (MEXU, MO); reserva de la Biosfera de Calakmul, 22 Sep 1991, Ortega 1724 (UADY); a 4 km al SE de La Nueva Vida, 2 Ago 1997, Martínez et al. 27934 (MEXU, MO); a $10 \mathrm{~km}$ al SE de Ley de Fomento Agropecuario, camino a Dos Naciones, 23 Oct 1997, Martínez et al. 29151 (MEXU, MO); a $9 \mathrm{~km}$ al SE de Dos Naciones, camino a El Civalito, 23 Oct 1997, Martínez et al. 29232 (MEXU, MO); a 6 km al NO de Dos Naciones, camino a Ranchería El Sacrificio, 27 Oct 1997, Martínez et al. 29501 (MEXU, MO); a $15 \mathrm{~km}$ al S de La Nueva Vida, camino a Xpujil, 12 Oct 1997, Martínez et al. 28777 (MEXU, MO); a 16 km al NE de Zoh-Laguna, 4 Ago 1997, Martínez et al. 28051 (MEXU, MO). Municipio Campeche. $3 \mathrm{~km}$ al S de Ejido Libertad, 7 Nov 1984, Ortiz 706 (CICY). Municipio Champotón. Tuxpeña, 21 Feb 1932, Lundell 1363 (MO, WIS). Municipio Escárcega. Campo Experimental Forestal El Tormento, $4 \mathrm{~km} \mathrm{O}$ de Escárcega, 10 May 1982, Davidse et al. 20293 (MO). Municipio Hopelchén. 3 km al SO de Cankabchen, 25 Sep 1984, Ortiz s.n. (CICY); a $0.53 \mathrm{~km}$ al SE del poblado 
Chan-Chén, 10 Dic 2003, Álvarez y Jiménez 7565 (CICY, MEXU, MO); 11 km al sur de la frontera Yucatán - Campeche, cerca de San Antonio Yaax-ché, 20 Sep 1999, Carnevali et al. 5694 (UADY); 4 km del camino a Uyamón, 20 Sep 1983, Ortiz 366 (CICY); Xmaben, Ejido Chan Chen, camino hacia sabana Xpujil, km 2, 24 Sep 2015, Ortiz 2540 (UADY). Quintana Roo: Municipio Benito Juárez. 3 km O de Puerto Morelos en la carretera a Vallarta, 5 May 1982, Davidse et al. 20060A (MO). Municipio Cozumel. Isla Cozumel, carretera transversal, km 12, 20 Sep 1983, Ortiz 893 (CICY, ITIC, MO). Municipio José María Morelos. Chichankanab, 1895, Gaumer 1461 (F). Municipio Lázaro de Cárdenas. A 3 km al Noreste del Rancho “El Edén”, 28 Nov 1991, Ortiz 1730 (UADY). Municipio Othón P. Blanco. Carretera a Tomás Garrido, entre Dos Aguadas y Tres Garantías, 15 Mar 1990, Ortiz y Ucán 1485 (UADY); predio Pablo Caballero, ejido Juan Sarabia, 20 Oct 1982, Ortiz s.n. (CICY); 9 km S a San José de la Montaña, 9 May 1982, Davidse et al. 20250 (MO). Municipio Tulum. 2 km al S de Akumal, 6 May 1982, Davidse et al. 20116 (MO). Yucatán: Municipio Hunucmá. Reserva el Palmar, 26 Feb 2007, Ortiz 2662 (UADY). Municipio Opichén. Carretera Muna - Opichén, km 10, 24 Sep 1984, Ortiz 560 (CICY, MO). Municipio Oxkutzcab. Xul-camino antiguo a Ticul, sin fecha, Sanabria et al. 130 (CICY). Municipio Panabá. 3-5 km al N del Rancho Ongay, 16 Jun 1991, Tun 265 (UADY). Municipio Tekax. Carretera Nohalal - Huntochac, km 4.5 sobre la carretera que cruza la sabana Nohchchakan, 7 Sep 2002, Ortiz y Magaña 2148 (UADY). Municipio Valladolid. Pixoy, camino rumbo a San Lorenzo, 27 Jun 1988, De Voyer 59 (CICY) (Fig. 2A).

Paspalum clavuliferum C. Wright, Anales Acad. Ci. Med. Habana 8: 203. 1871. TIPO: CUBA. “Cuba Oriental”, C. Wright 3444 (holotipo, GH; isotipos, B, NY71066, NY-71067, US-2942143) (Fig. 1D).

Ic. Pohl, R. W., Flora Costaricensis. Fieldiana, Bot. 4(15): 410. 1980.

Anuales cespitosas. Culmos erectos, ramificados, $10-80 \mathrm{~cm}$ alto; entrenudos y nudos glabros. Hojas con vainas comprimidas lateralmente, densa a esparcidamente papiloso-pilosas; lígula 0.6-1.7 mm; láminas 3-15 cm largo, 1.5-3.5 mm ancho, lineares, aplanadas, papiloso-pilosas, márgenes glabros. Sinflorescencia $2-5 \mathrm{~cm}$ largo con 1-2 racimos de 4-5 cm largo, conjugados cuando 2, raramente con un tercero por debajo, ascendentes, laxos; raquis 0.3-0.5 mm de ancho, angosto, escabriúsculo, con una espiguilla en el ápice, triquetro. Espiguillas 1.1-1.4 mm largo y 0.6-0.8 mm ancho, elíptico-obovadas, pareadas, en 2-4 filas; gluma inferior ausente; gluma superior y lema inferior tan larga como la espiguilla, gluma inferior glandular-pelosa con 
tricomas capitelados, obtusas, con 3 nervios; lema inferior glabra, obtusa, 2-3 nervios. Flósculo superior 1.1-1.4 mm largo, diminutamente papiloso, amarillo pálido.

Esta especie florece en julio y agosto. Se encuentra en pastizales secos, en sabanas y áreas abiertas en selva baja caducifolia, alrededor de los $100 \mathrm{~m}$ altitud. En el territorio estudiado se la conoce de Campeche y Yucatán. En México se encuentra además en Chiapas, Colima, Guerrero, Jalisco, Michoacán, Nayarit, Oaxaca, Sinaloa y Tamaulipas. Su distribución abarca México, Mesoamérica (Belice, Costa Rica, Guatemala, Honduras, Nicaragua, El Salvador, Panamá) y Sudamérica (Bolivia, Brasil, Colombia, Guyana, Venezuela) y las Antillas (Cuba, República Dominicana, Haití, Puerto Rico).

Ejemplares examinados: Campeche: Municipio Calkiní, carretera Calkiní El Remate, 6 km después de Tankuché, 12 Sep 1983, Ortiz 358 (CICY). Municipio Hopelchén. Carretera Dzibalchén - Pich, 1 Oct 2003, Ortiz y Miranda 2288 (CICY). Yucatán: Municipio Yaxcabá. Tixcacaltuyub, Mar 1988, Rico 782 (MEXU, MO) (Fig. 2A).

Paspalum conjugatum P. J. Bergius, Acta Helv. Phys.-Math. 7: 129, f. 8.1762 (1772). TIPO (lectotipo designado por Koning \& Sosef, Blumea 30: 290, 293. 1985): SURINAM. Sin localidad, Rolander in Herb. Bergius 36 SBT (Fig. 1E). Ic. Allen, C. M. y D. W. Hall. 2003. Paspalum L. In: Flora of North America Editorial Committee, eds. 1993+. Flora of North America North of Mexico 16+ vols. New York and Oxford. Vol. 25(2): 574.

Perennes, estoloníferas. Culmos erectos, ramificados, 30-50(-100) cm alto; entrenudos glabros; nudos glabros o pelosos. Hojas con vainas comprimidas lateralmente, glabras o generalmente ciliadas; lígula 0.3-0.5 mm largo; láminas 10-20 cm largo, 7-15 mm ancho, lineares, aplanadas, glabras o menos frecuentemente pilosas, márgenes escabrosos o cortamente ciliados. Sinflorescencia 6-16 cm largo con 2 racimos de 6-16 cm largo, conjugados, raramente con un tercero por debajo, patentes a flexuosos, laxos; raquis $0.5-1 \mathrm{~mm}$ de ancho, angostamente alado, pubescente en la base, sin espiguilla en el ápice, triquetro. Espiguillas 1.3-1.7 mm largo, 1-1.2 mm ancho, ovadas, solitarias, en 2 filas; gluma inferior ausente; gluma superior y lema inferior tan larga como la espiguilla, gluma superior papilosociliada en los márgenes, subaguda y apiculada, con 2 nervios; lema inferior glabra, subaguda y apiculada, con 2 nervios. Flósculo superior 1.3-1.5 mm largo, liso, blanquecino. 
Esta especie florece de mayo a octubre. Es característica de áreas abiertas y húmedas, márgenes de ríos, entre los 9-240 m altitud. Paspalum conjugatum es ampliamente usada en prados umbrosos y frecuentemente se asocia con Axonopus fissifolius (Raddi) Kuhlm. En el territorio estudiado se ha registrado su presencia en Campeche, Quintana Roo y Yucatán. En México se ha localizado además en los estados de Chiapas, Coahuila, Colima, Durango, Guerrero, Hidalgo, Jalisco, México, Michoacán, Morelos, Nayarit, Nuevo León, Oaxaca, Puebla, Querétaro, San Luis Potosí, Sinaloa, Tabasco, Tamaulipas y Veracruz. Su distribución abarca Estados Unidos de América (Alabama, Florida, Luisiana, Misisipi, Texas, Utah), México, Mesoamérica (Belice, Costa Rica, Guatemala, Honduras, Nicaragua, Panamá, El Salvador), Sudamérica (Argentina, Brasil, Bolivia, Colombia, Ecuador, Galápagos, Guayanas, Perú, Surinam, Venezuela) y Antillas (Bahamas, Islas Barlovento, Bermudas, Cuba, República Dominicana, Haití, Jamaica, Puerto Rico, Trinidad y Tobago). Presente en el trópico del Viejo Mundo.

Ejemplares examinados: Campeche: Municipio Calakmul. Calakmul $500 \mathrm{~m}$ al N del poblado, 14 Oct 1997, Lira et al. 195 (MEXU, MO), 17 Jul 1998, Madrid y Arandia 1040 (MO); a $1 \mathrm{~km}$ al N del Poblado Narciso Mendoza, Álvarez 136 (MO), 20 Sep 1997, Álvarez 375 (MO); a 10 km al SE de Ley Fomento Agropecuario, camino a Dos Naciones, 23 Oct 1997, Martínez et al. 29281 (CICY, MO), 29 Jul 1997, Martínez et al. 27851 (MEXU). Municipio Campeche. Chiná, 14 Oct 2008, Carvajal 17 (UADY); carretera Champotón - Isla Aguada, rancho Nohan-San Pablito, 8 Nov 1984, Ortiz 727 (CICY). Municipio Champotón. Camino Hool - Arellano, 3 Nov 1981, Ortiz 184 (CICY). Municipio Escárcega. 3 km al S de Ejido Libertad, 7 Nov 1984, Ortiz 712 (CICY). Municipio Hopelchén. Conhuas a $25 \mathrm{~km}$ al S, hacia El Ramonal, 8 Dic 1990, Ucan et al. 6506 (UADY); carretera Dzibalchén - Pich, Ejido San Miguel Allende, 1 Oct 2013, Ortiz y Miranda 2308 (UADY). Quintana Roo: Municipio Othón P. Blanco. Río Hondo, El Palmar, 8 May 1982, Davidse et al. 20218 (MO), ejido La Unión, 14 May 1985, Ortiz 853 (CICY); zona arqueológica Kohunlich, 19 May 2008, Ortiz y Tun 2843 (UADY); predio Pablo Caballero, ejido Juan Sarabia, 20 Oct 1982, Ortiz s.n. (UADY). Municipio Solidaridad. Zona arqueológica Muyil, 7 Jul 1983, Durán y Olmstead 298 (CICY). Municipio Tulum. Zona arqueológica Cobá, 30 Jun 1984, Ortiz 510 (CICY). Yucatán: Municipio Tizimín. 1 km al E de Ejido Santa Clara, 12 Nov 1992, Kú y Yam 225 (CICY). (Fig. 2B).

Paspalum corcovadense Raddi, Agrostogr. Bras. 27-28. 1823. TIPO: BRASIL. Río de Janeiro: Río de Janeiro, Monte Corcovado, sin fecha, G. Raddi s.n. (holotipo, PI; isotipos, F, US-2942132) (Fig. 1F).

Ic. Renvoize, R. A., The grasses of Bahia: 232. 1984. 

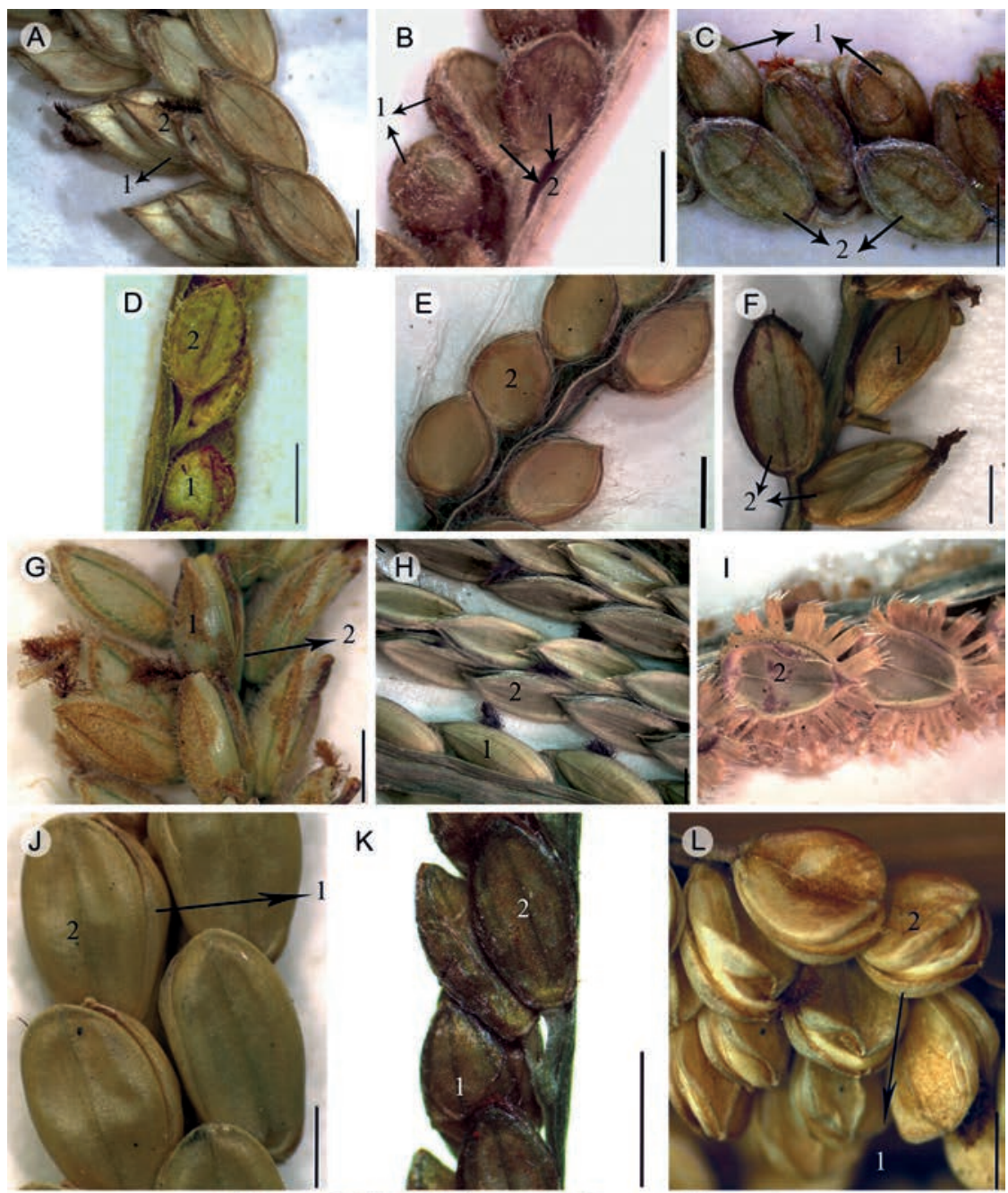

$\mathrm{K}$
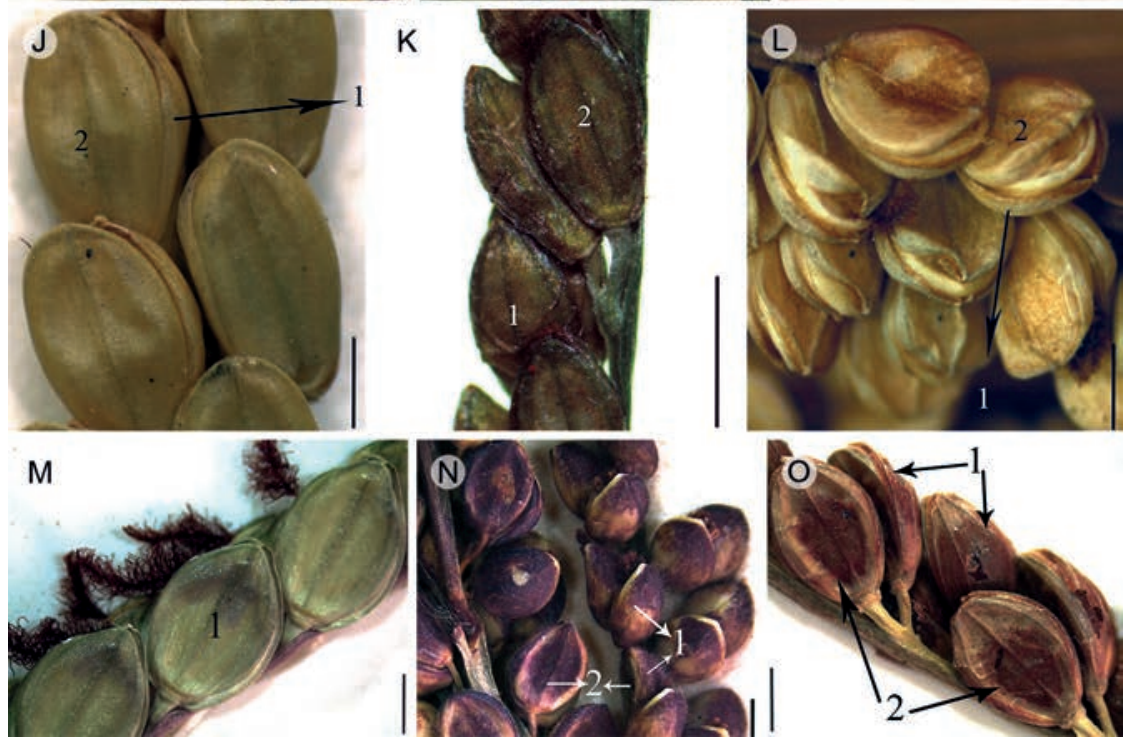

Fig. 1. Detalle de las espiguillas de: A. P. alcalinum; B. P. blodgettii; C. P. caespitosum; D. P. clavuliferum; E. P. conjugatum; F. P. corcovadense; G. P. coryphaeum; H. P. fasciculatum; I. P. fimbriatum; J. P. ligulare; K. P. mayanum; L. P. millegrana; M. P. notatum var. notatum; N. P. paniculatum; O. P. plicatulum. 

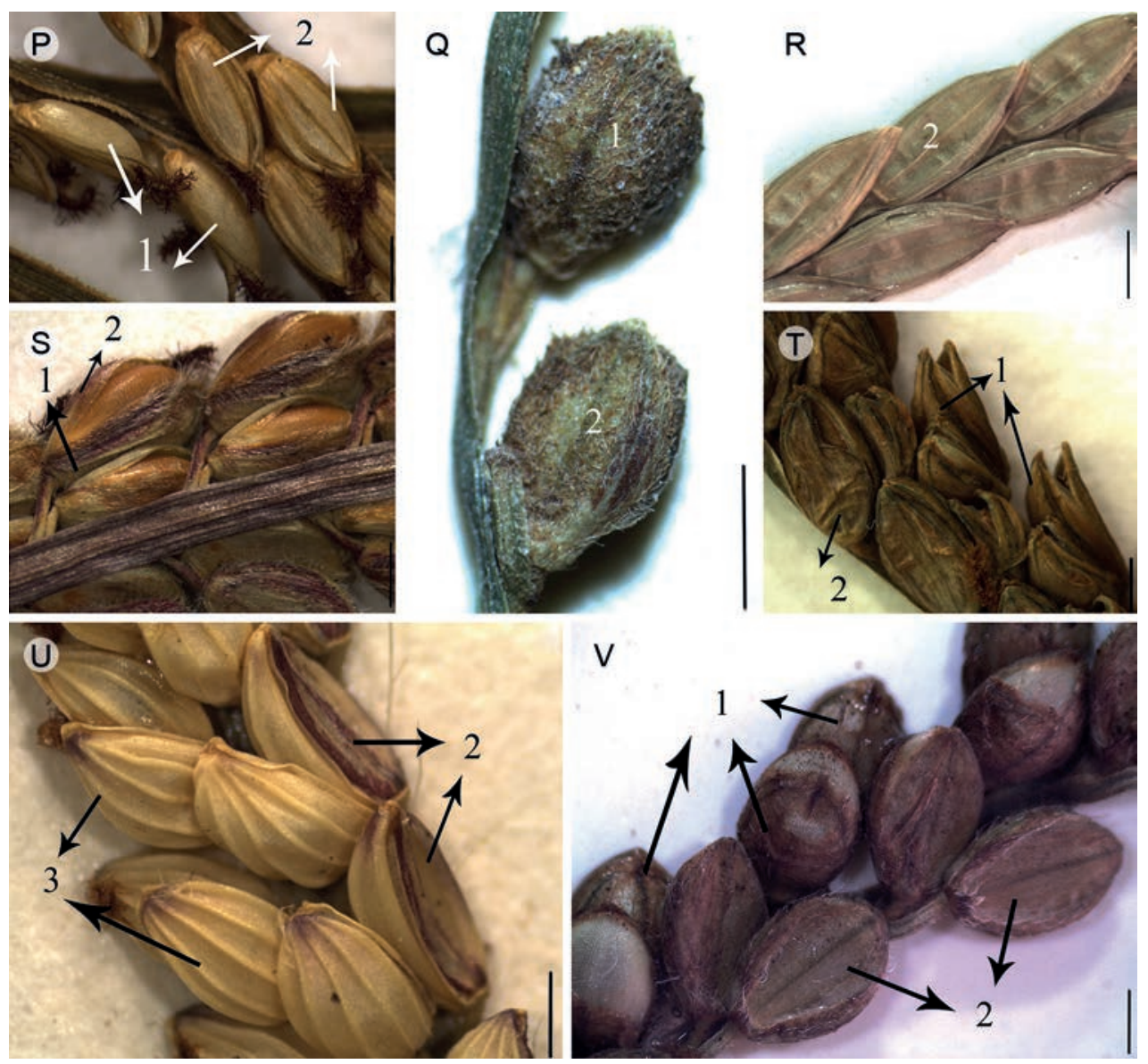

Fig. 1. Continuación. P. P. repens; Q. P. sparsum; R. P. vaginatum; S. P. virgatum; T. P. wrightii; U. P. malacophyllum; V. P. botterii. 1. gluma superior; 2. lema inferior; 3. lema superior. Escala $1 \mathrm{~mm}$.

Perennes, cespitosas, bases nodulosas. Culmos erectos o ascendentes, simples, 30-100 cm alto; entrenudos y nudos glabros. Hojas con vainas comprimidas, pelosas en el margen y hacia el ápice; lígula 0.7-2.5 mm largo; láminas 15-30 cm largo, 7-15 $\mathrm{mm}$ de ancho, lineares, aplanadas, esparcidamente pelosas y adpreso pubescente en el envés, márgenes ciliados hacia la base. Sinflorescencia 9-17 cm con 2-8 racimos de 4-9 cm largo, de ascendentes o divergentes, laxos; raquis 0.3$0.5 \mathrm{~mm}$ de ancho, angosto, glabrescente, con una espiguilla en el ápice, triquetro. Espiguillas 2-2.5 mm largo, 1-1.1 mm de ancho, elípticas, solitarias o raramente 
pareadas, en (2)4 filas; gluma inferior ausente; gluma superior ligeramente más corta que la espiguilla, esparcidamente adpreso pelosa, obtusa, con 3-5 nervios; lema tan larga como la espiguilla, glabra o esparcidamente pelosa en los márgenes, obtusa, con 3-5 nervios. Flósculo superior 2.3 mm largo, liso, amarillo pálido.

Esta especie florece en julio. Se encuentra en áreas húmedas abiertas en la selva mediana subcaducifolia, alrededor de los $30 \mathrm{~m}$ de altitud. Dávila et al. (2006) citan P. corcovadense para el estado de Campeche pero hasta ahora el único ejemplar revisado para la región fue colectado en Yucatán. En México, también se ha registrado en los estados de Chiapas, Oaxaca, Tamaulipas y Veracruz. Se distribuye desde México, Mesoamérica (Belice, Honduras) a Sudamérica (Brasil, Guyana, Venezuela y Perú).

Ejemplar examinado: Yucatán: Municipio Tinum. Chichén Itzá, 7 al 13 Jul 1932, Swallen 2431 (MEXU, MO, US) (Fig. 2B).

Paspalum coryphaeum Trin., Gram. Panic. 114. 1826. TIPO: BRASIL. Brasilia, Langsdorff s.n. (holotipo, LE) (Fig. 1G).

Ic. Pohl, R. W., Flora Costaricensis. Fieldiana, Bot. 4(15): 415. 1980.

Perennes, cespitosas. Culmos erectos, simples o ramificados, 100-200 cm alto; entrenudos pilosos a glabros, nudos pilosos. Hojas con vainas redondeadas, papiloso-híspidas; lígula de 2-3 mm; láminas 14-50 cm largo, 10-20 mm ancho, lineares, aplanadas, glabras a puberulentas, márgenes escábridos y revolutos. Sinflorescencia 4-25 cm largo con 12-14 racimos de 4-12 cm largo, patentes a péndulos, laxos; raquis 0.3-0.4 mm largo, generalmente escabriúsculo marginalmente o ciliado con pelos de 5-6 mm largo, con una espiguilla en el ápice, triquetro. Espiguillas de 1.1-2 mm largo, 0.7-1 mm de ancho, elípticas, pareadas, en 4 filas; gluma inferior ausente; gluma superior y lema inferior casi tan larga como la espiguilla, la gluma superior papiloso pelosa, subaguda, con 3 nervios; lema inferior de glabra a papiloso-pelosa, subaguda, con 3 nervios. Flósculo superior 2-2.3 $\mathrm{mm}$ largo, finamente estriado, blanquecino.

Esta especie florece de julio a octubre. En el territorio estudiado se encuentra en sabanas hasta los $100 \mathrm{~m}$ de altitud. En México únicamente se encuentra en la Península de Yucatán en los estados de Campeche y Yucatán. Ha sido introducida en Estados Unidos de América (Florida, North Carolina) y se distribuye 
en México, Mesoamérica (Belice, Honduras, Panamá, Costa Rica) hasta el norte de Sudamérica (Brasil, Colombia, Guyanas, Surinam, Venezuela) y las Antillas (Trinidad y Tobago).

Ejemplares examinados: Campeche: Municipio Hopelchén. Carretera Dzibalchén - Pich, Ejido San Miguel Allende, 1 Oct 2013, Ortiz y Miranda 2308 (CICY, UCAM). Yucatán: Municipio Tekax. Carretera Nohalal - Huntochac, km 4.5, al SE sobre la carretera que cruza la sabana Nohochchakan, 10 Oct 2003, Ortiz y Magaña 2332 (CICY, UADY) (Fig. 2B).

Paspalum fasciculatum Willd. ex Flüggé, Gram. Monogr., Paspalum: 69. 1810. TIPO (lectotipo designado por Chase, Contr. U.S. Natl. Herb. 28(1): 179. 1929): BRASIL. Sin localidad, J. C. von Hoffmannsegg s.n., B-W; isotipos, BM, SI, P, US2855329). (Fig. 1H).

Ic. Pohl, R. W., Flora Costaricensis. Fieldiana, Bot. 4(15): 421. 1980.

Perennes estoloníferas. Culmos decumbentes y enraizando, simples o ramificados, hasta $200 \mathrm{~cm}$ alto; entrenudos y nudos glabros a pilosos. Hojas con vainas carinadas, glabras o piloso-híspidas; lígula 0.5-2.5 mm largo; láminas 22-45 cm largo, 10-20 mm ancho, anchamente lineares, aplanadas, glabras a pilosas, márgenes escabrosos. Sinflorescencia 6-18 cm largo, flabeliforme, con 14-25 racimos de 7-16 cm largo, ascendentes a péndulos, laxos; raquis 0.8-1.2 mm de ancho, escabroso en el margen, en ocasiones esparcidamente ciliado con pelos de 6-7 mm, sin o con espiguilla en el ápice, aplanado. Espiguillas 3.7-4.6 mm largo, 1.5-1.8 mm ancho, elíptico-lanceoladas, solitarias, en dos filas; gluma inferior ausente o diminuta; gluma superior y la lema inferior tan largas como la espiguilla, ciliadas en los márgenes, acuminadas, con 3-7-nervios. Flósculo superior 3.8-4.2 mm largo, diminutamente estriado, pardo claro.

Esta especie florece de agosto a octubre. Su hábitat característico es el manglar y lugares abiertos húmedos en altitudes cercanas al nivel del mar. En el terrritorio estudiado solo se ha detectado la presencia de esta especie en Campeche. Sin embargo, en México se la conoce también de Chiapas, Jalisco, Nayarit, Oaxaca, Tabasco y Veracruz. A nivel mundial se distribuye desde el sur de México, Mesoamérica (Belice, Costa Rica, Guatemala, Honduras, El Salvador, Nicaragua, y Panamá) hasta Sudamérica (Argentina, Brasil, Colombia, Ecuador, Guayana Francesa, Paraguay, Perú, Surinam, Uruguay, Venezuela) y las Antillas (Islas de Barlovento, Cuba, República Dominicana, Haití, Puerto Rico, Trinidad y Tobago). 
Ejemplar examinado: Campeche: Municipio Champotón. Champotón, 27 Sep 1984, Ortiz 670 (CICY) (Fig. 2B).

Paspalum fimbriatum Kunth, Nov. Gen. Sp. 1: 93-94, t. 28. 1815 (1816). TIPO: COLOMBIA. Rescit in siccis prope Ibague et in devexis montis Quelamanae (Regno Novogranatensi), floret Octobri, Humboldt \& Bonpland s.n. (holotipo, P; isotipo, US-2855335) (Fig. 1I).

Ic. Allen, C. M. y D. W. Hall. 2003. Paspalum L. In: Flora of North America Editorial Committee, eds. 1993+. Flora of North America North of Mexico 16+ vols. New York and Oxford. Vol. 25(2): 580.

Anuales cespitosas. Culmos erectos o decumbentes, ramificados desde la base, 40-85 cm alto; entrenudos glabros, nudos glabros o pilosos. Hojas con vainas comprimidas, esparcidamente ciliadas o glabras; lígula 1-2.5(5) mm largo; láminas 11-30 cm largo, 8-18 mm ancho, lineares, aplanadas, glabras a más o menos papiloso-hirsutas, ciliadas, márgenes cortamente híspidos hacia la base. Sinflorescencia 4-14 cm largo con 4-6 racimos de 3.5-8 cm largo, patentes, laxos; raquis 1.2-2 mm de ancho, escabroso en el margen o esparcidamente ciliado, con una espiguilla en el ápice, aplanado. Espiguillas 2.8-3.2 mm largo, $3 \mathrm{~mm}$ ancho, orbiculares, pareadas, en 4 filas; gluma inferior ausente; gluma superior y lema inferior tan largas como la espiguilla, gluma superior marcadamente alada, el ala cartilaginosa, fimbriada, acuminada, apiculada, con 3 nervios, lema inferior generalmente menos alada que la gluma, acuminada, apiculada, con 3 nervios. Flósculo superior 2.5-2.8 mm largo, diminutamente papiloso, amarillo pálido.

Esta especie florece de agosto a octubre. Se localiza en áreas abiertas, entre los 10-270 m altitud. En el territorio estudiado se conoce de Campeche, Quintana Roo y Yucatán. En México ha sido citada también del estado de México. Ha sido introducida en Asia y Estados Unidos de América (Florida, Hawái). Se distribuye en Mesoamérica (Belice, Guatemala y Panamá), Sudamérica (Brasil, Colombia, Guayana Francesa, Venezuela) y Antillas (Bahamas, Islas de Barlovento, Islas Bermudas, Islas Caymán, Cuba, República Dominicana, Haití, Jamaica, Puerto Rico, Trinidad y Tobago).

Ejemplares examinados: Campeche: Municipio Campeche. Chiná, 24 Oct 2008, Carvajal 26 (UADY). Municipio Champotón. Entre Chicana y Chichonal, carretera a Chetumal, 4 Jul 1995, Zamora 4643 (CICY). Quintana Roo: Municipio Othón P. Blanco. Chetumal, 8 May 1982, Davidse et al. 20238 (MO); ejido Limones, 
predio Sabanita, 21 Oct 1982, Ortiz s.n. (CICY). Yucatán: Municipio Oxkutzcab. Grutas de Lol-Tun, 14 Jul 1983, Lira y Ortiz 378 (CICY). Municipio Santa Elena. Ruinas de Uxmal, 27 Oct 1984, Pohl 14544 (F, MO) (Fig. 2B).

Paspalum ligulare Nees, Fl. Bras. Enum. Pl. 2: 60. 1829. TIPO: BRASIL. Bahia, hábitat in apricis, sylvis caeduis passim obsitis, granitics ad Feira de S. Anna et in Monte Sancto provinciae Bahiensis, Anon. (holotipo M; isotipo US-800077) (Fig. 1J).

= Paspalum setaceum var. dispar R. Guzmán, Phytologia 51(7): 469. 1982. TIPO: MÉXICO. Oaxaca, low-lying hills near the Pacific Ocean, $2 \mathrm{~km}$ E of Salina Cruz, vegetation mainly of thorny leguminous shrubs and cacti growing in open field in sandy loam, in association with other grasses, 25 Jun 1958, R. M. King 187 (holotipo, MEXU).

Ic. Renvoize, R. A., The grasses of Bahia: 210. 1984.

Perennes, cespitosas. Culmos erectos, simples, 50-120 cm alto; entrenudos y nudos glabros. Hojas con vainas comprimidas longitudinalmente, ciliadas; lígula 1.5-2 mm largo; láminas 15-35 cm largo, 3-7 mm ancho, lineares, aplanadas, escábridas, ciliadas, márgenes glabros. Sinflorescencia $15-20 \mathrm{~cm}$ largo con 4-6 racimos de 5-8.5 cm largo, ascendentes, laxos; raquis 1-1.2 mm ancho; angosto, escabroso, con una espiguilla en el ápice, triquetro. Espiguillas 2.2-2.5 mm largo, $1.8 \mathrm{~mm}$ ancho, elíptico-obovadas, pareadas, en 4 filas; gluma inferior ausente; gluma superior y lema inferior tan largas como la espiguilla, glabrescentes, obtusas, la gluma superior apiculada, ambas con 3-5 nervios. Flósculo superior 2-2.3 mm largo, estriado, amarillo pálido.

La floración de esta especie ocurre en junio. Se encuentra en la vegetación riparia cercana a nivel del mar. En el territorio estudiado solamente se conoce de Campeche, en México también se ha detectado su presencia en Jalisco, Oaxaca y Veracruz. Se distribuye desde México, Mesoamérica (Belice, Guatemala, Honduras y Nicaragua) a Sudamérica (Venezuela y Brasil).

Ejemplar examinado: Campeche: Municipio Champotón. Carretera Champotón - Ulumal, Río Champotón donde cruza el puente entre El Zapotal y Ulumal, 6 Jun 1997, Carnevali et al. 4651 (UADY) (Fig. 2C).

Paspalum mayanum Chase, Publ. Carnegie Inst. Wash. 436: 342, f. 6. 1934. TIPO: MÉXICO. Yucatán, along trail through brush, Uxmal, 20-21 Jul 1932, J. R. Swallen 2623 (holotipo, US-1537457) (Fig. 1K). 
Ic. Swallen, J. R., The grasses of the Yucatan Peninsula. Publ. Carnegie Inst. Wash. 436: 342. 1934.

Perennes, cespitosas. Culmos erectos, simples, $55-70 \mathrm{~cm}$ alto; entrenudos y nudos glabros o pilosos. Hojas con vainas redondeadas, papiloso-ciliadas; lígula 0.51 mm largo; láminas 8-15 cm largo, 6-12 mm ancho, lineares, aplanadas, papilosociliadas, velutinas en el haz, márgenes híspidos. Sinflorescencia 2-9 $\mathrm{cm}$ largo con 2-4 racimos de 1.3-5 cm largo, ascendentes, laxos; raquis 0.5-0.7 $\mathrm{mm}$ de ancho, glabro, con una espiguilla en el ápice, triquetro. Espiguillas 1.5-1.8 mm largo, 0.8-0.9 $\mathrm{mm}$ ancho, obovadas, pareadas, en 4 filas; gluma inferior ausente; gluma superior y lema inferior tan largas como la espiguilla, esparcidamente adpreso-pelosas, obtusas, gluma superior con 5 nervios, lema inferior con 3 nervios. Flósculo superior 1.5-1.6 mm largo, liso, glabro, amarillo pálido.

Esta especie florece en los meses de julio a septiembre y habita en áreas abiertas de la selva baja caducifolia, entre los 8-50 m de altitud. Es endémica de la Península de Yucatán.

Ejemplares examinados: Campeche: Municipio Calakmul. A $1 \mathrm{~km}$ al $\mathrm{N}$ de Narciso Mendoza, camino a Xpujil, 16 Oct 1997, Álvarez et al. 467 (MEXU, MO). Yucatán: Municipio Halachó. Carretera Santa María Acu - San Mateo, km 2.8, 29 Nov 2001, Ortiz y Magaña 2107 (UADY). Municipio Santa Elena. Uxmal, 20-30 Jul 1932, Swallen 2623 (MEXU, US) (Fig. 2C).

Paspalum millegrana Schrad., Mant. 2: 175. 1824. TIPO: BRASIL. Brasilia, Princeps Sereniss. Maximilian Neowidensis s.n. (holotipo, B?) (Fig. 1L).

= Paspalum karwinskyii E. Fourn., Mexic. Pl. 2: 8. 1886. TIPO: MÉXICO. Savana Grande, entre el Chapopote y Tamalor, W. F. Karwinski 1476 (holotipo, LE; isotipo, US-2855293)

Ic. Renvoize, S. A, Gramíneas de Bolivia: 474. 1998.

Perennes, cespitosas. Culmos erectos, simples, 120-200 cm alto; entrenudos y nudos glabros. Hojas con vainas no comprimidas, glabras; lígula de 1-2 mm; láminas 70-150 cm largo, 5-12 mm ancho, lineares, rígidas, plegadas cerca de la base, por lo demás aplanadas, escábridas en el envés, más o menos pelosas en el haz, márgenes glabrescentes. Sinflorescencia 20-25 cm largo, con 6-14(20) racimos de 6-12 cm largo, ascendentes a patentes, laxos; raquis 1-1.2 de mm de ancho, escabroso y esparcidamente ciliado, con una espiguilla en el ápice, triquetro. Espiguillas 
2-2.5 mm largo, 1.8-2 mm ancho, suborbiculares, pareadas, en 4 filas; gluma inferior ausente; gluma superior y lema inferior escasamente más cortas que la espiguilla, glabras, obtusas, cortamente apiculadas, con 3 nervios. Flósculo superior 2-2.5 mm largo, papiloso-estriado, amarillo pálido.

Esta especie florece de junio a agosto. Habita lugares con suelos inundados y charcos permanentes en la selva baja inundable, así como en suelos húmedos arenosos en transición de manglar con dunas costeras y vegetación secundaria ruderal y zanjas de riego, en altitudes cercanas al nivel del mar. En el territorio estudiado se encuentra en los tres estados y en México además en Chiapas, Querétaro, San Luis Potosí, Tabasco, Tamaulipas y Veracruz. Su distribución abarca México, Mesoamérica (Belice, Honduras, Nicaragua, Panamá, El Salvador), hasta Sudamérica (Bolivia, Brasil, Venezuela, Colombia, Guayanas, Surinam) y las Antillas (Bahamas).

Ejemplares examinados: Campeche: Municipio Calkiní. Alrededor del El Remate, 18 Oct 1984, Chan 4326 (CICY, UADY), 5 Sep 1980, Palma y Alkin 275 (CICY, XAL); carretera Tankunché - El Remate, entre San Nicolás y Tankuché, 22 Sep 2003, Ortiz 2240 (CICY, UADY). Municipio Hopelchén. Ejido Becanchén, 24 Sep 1984, Ortiz 541 (CICY, XAL). Quintana Roo: Municipio Benito Juárez. NE de Ciudad Cancún, 8 Jul 1992, Ucán et al. 8492 (UADY). Municipio Ciudad del Carmen. 3 km al E de Ciudad del Carmen, 19 Sep 2000, Gutiérrez y Contreras 7051 (CICY). Yucatán: Municipio Santa Elena. Uxmal, 20-21 Jul 1932, Swallen 2634 (MO) (Fig. 2C).

Paspalum notatum Alain ex Flüggé var. notatum, Gram. Monogr., Paspalum 106. 1810. TIPO (lectotipo designado por Koning \& Sosef, Blumea 30(2): 313. 1985): ISLAS VÍRGENES. St. Thomas, E. P. Ventenat s.n., 1802, BM, SI; isotipos, MO, P-LA, US-2855762, fragmento ex BM (Fig. 1M).

Ic. Zuloaga, F. O. et al., Syst. Bot. Monogr. 71: 48. 2004.

Perennes, con rizomas gruesos, escamosos. Culmos erectos, simples, $40-70 \mathrm{~cm}$ largo; entrenudos glabros. Hojas con vainas comprimidas longitudinalmente, glabras o ciliadas; lígula 0.3-0.5 mm largo; láminas 3-12 cm largo, 4-10 mm ancho, lineares, aplanadas pero plegadas hacia la base, glabras, ciliadas en la base, márgenes glabrescentes. Sinflorescencia 4-8 cm largo con 2 racimos de 4-8 cm largo, conjugados, laxo; raquis 0.7-0.9 $\mathrm{mm}$ de ancho, en zigzag, glabro, con una espiguilla en el ápice y las superiores abortivas, triquetro. Espiguillas 3.5-3.8 mm largo, 2.5-2.8 mm ancho, 
ovadas a obovadas, solitarias, en 2 filas; gluma inferior generalmente ausente; gluma superior y lema inferior tan largas como la espiguilla, glabras, obtusas, con 5 nervios. Flósculo superior 2.3-3.3 mm largo, diminutamente estriado, amarillo pálido.

Esta variedad florece de julio a agosto. Se encuentra en pastizales y áreas abiertas perturbadas, entre 15-220 m de altitud. En el territorio en estudio se encuentra en Campeche y Yucatán, y en México, además de estos dos estados, también se la conoce de Aguascalientes, Chiapas, Colima, Distrito Federal, Durango, Guanajuato, Guerrero, Hidalgo, Jalisco, México, Michoacán, Morelos, Nayarit, Nuevo León, Oaxaca, Puebla, Querétaro, San Luis Potosí, Sinaloa, Sonora, Tabasco, Tamaulipas, Veracruz y Zacatecas. Es una planta introducida en Estados Unidos de América y el
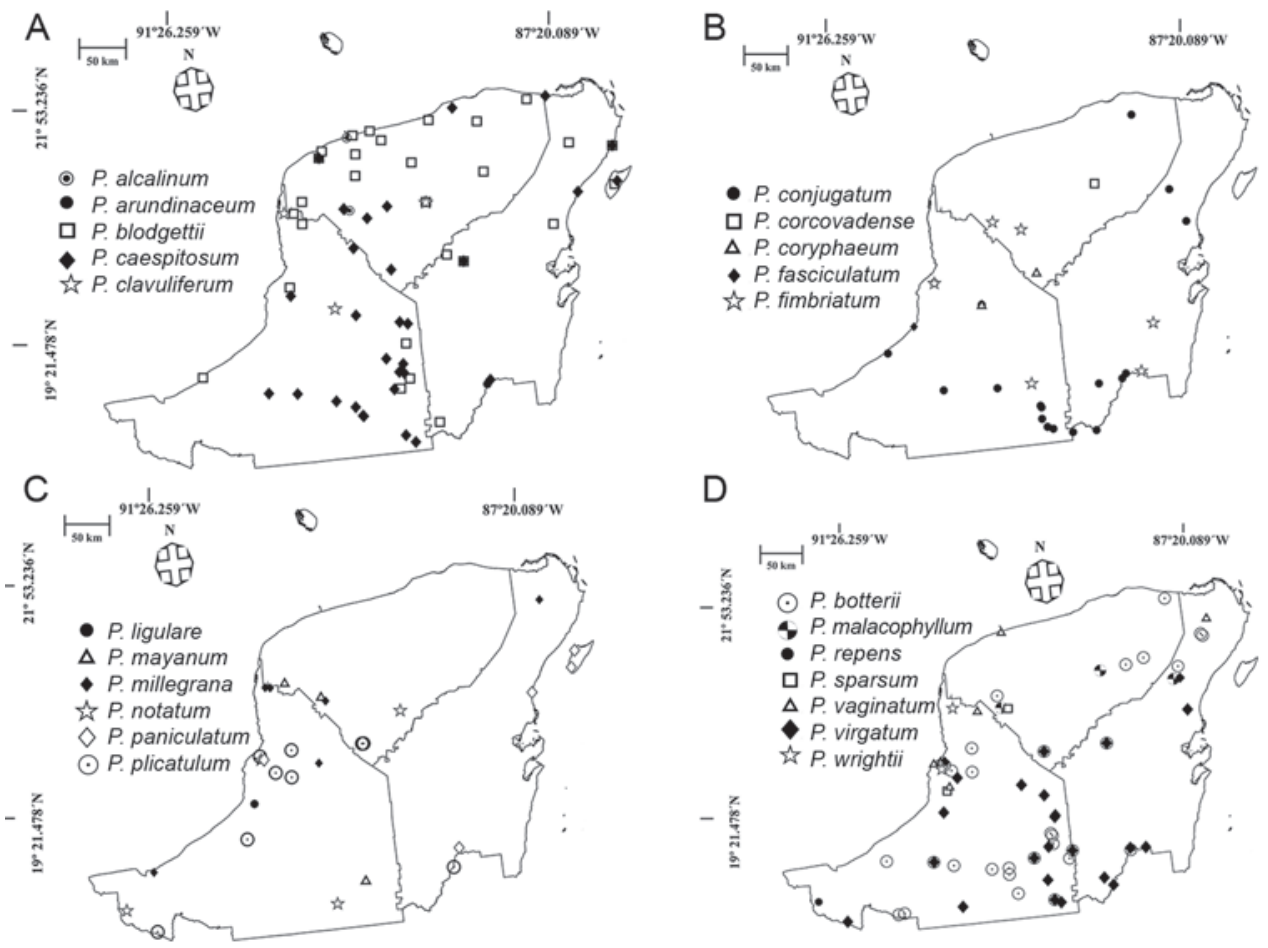

Fig 2. Distribución geográfica en la Península de Yucatán de Paspalum. A. P. alcalinum, P. arundinaceum, P. blodgettii, P. caespitosum y P. clavuliferum; B. P. conjugatum, P. corcovadense, $P$. coryphaeum, $P$. fasciculatum, P. fimbriatum; C. P. ligulare, P. mayanum, $P$. millegrana, $P$. notatum var. notatum, $P$. paniculatum y P. plicatulum; D. P. botterii, $P$. malacophyllum, P. repens, $P$. sparsum, $P$. vaginatum, $P$. virgatum y $P$. wrightii. 
viejo mundo y se distribuye en México, todo Mesoamérica, Sudamérica y las Antillas (Bahamas, Cuba, Jamaica, Puerto Rico, Antigua y Martinica).

Ejemplares examinados: Campeche: Municipio Calakmul. A $12 \mathrm{~km}$ al SO de Xpujil, en los alrededores de la zona arqueológica de Calakmul, 13 Ago 1996, Álvarez y Martínez 476 (MEXU, MO). Municipio Calkiní, Brecha Tankuché a El Remate, 20 Jul 1981, Chan 641 (CICY, XAL). Municipio Campeche. Chiná, alrededores del Campo Experimental INIFAP, Carvajal 13 (UADY). Municipio Palizada. Palizada, 17 Jun 1981, Ortiz 123 (MO). Yucatán: Municipio Peto. Peto, 26-27 Jul 1932, Swallen 2669 (US) (Fig. 2C).

Paspalum paniculatum L., Syst. Nat. ed. 10, 855. 1759. TIPO (lectotipo designado por Hitchcock, Contr. U.S. Natl. Herb. 12(3): 116. 1908): JAMAICA. Sin localidad, P. Browne s.n. LINN-79.7 (Fig. 1N).

Ic.: Pohl, R. W., Flora Costaricensis. Fieldiana, Bot. 4(15): 435. 1980.

Perennes, cespitosas, bases densamente hirsutas. Culmos generalmente erectos, ramificados, 30-100 cm alto; entrenudos glabros; nudos pilosos. Hojas con vainas comprimidas longitudinalmente, más o menos papiloso-híspidas; lígula 0.5-1 mm largo; láminas 9-30 cm largo, 10-15 mm ancho, anchamente lineares, aplanadas, híspidas o glabrescentes, márgenes ciliados, usualmente ondulados. Sinflorescencia 5-20 cm largo con 18 o más racimos o más de 2.6-9 cm largo, patentes, a veces arqueados, laxos; raquis $0.3 \mathrm{~mm}$ de ancho, esparcidamente pilosas con tricomas alargados, con una espiguilla en el ápice, triquetro. Espiguillas 1.3-1.5 mm de largo, 1-1.2 mm ancho, obovadas, pareadas, en 4 filas; gluma inferior ausente; gluma superior y lema inferior tan largas como la espiguilla, puberulentas, obtusas, no apiculadas, con 3 nervios. Flósculo superior 1.2-1.3 mm largo, diminutamente estriado, amarillo pálido.

Esta especie florece de julio a septiembre. Se encuentra formando parte de pastizales en áreas abiertas en la selva mediana subcaducifolia y en zonas perturbadas, entre los 7-30 m de altitud. En el territorio estudiado solamente se ha localizado en el estado de Quintana Roo; sin embargo, ha sido citada para Campeche y Yucatán (Dávila et al., 2006; Sánchez-Ken, 2010). En México se la conoce también de los estados de Aguascalientes, Baja California Sur, Chiapas, Colima, Guerrero, Jalisco, México, Michoacán, Morelos, Nayarit, Oaxaca, Puebla, San Luis Potosí, Sinaloa, Sonora, Tabasco, Veracruz y Zacatecas. Ha sido introducida en Estados Unidos de América (Florida, Misisipi) y los trópicos del Viejo Mundo. Se distribuye además 
en Mesoamerica (Belice, Guatemala, Honduras, Nicaragua, Panamá, Costa Rica, El Salvador), Sudamérica (Argentina, Bolivia, Brasil, Colombia, Ecuador, Galápagos, Guyanas, Paraguay, Perú, Surinam, Uruguay, Venezuela), las Antillas (Bahamas, Islas de Barlovento, Bermudas, Islas Caimán, Cuba, República Dominicana, Haití, Jamaica, Puerto Rico, Trinidad y Tobago).

Ejemplares examinados: Campeche: Municipio Campeche. Chiná, Campo Experimental INIFAP, 14 Oct 2008, Carvajal 16 (UADY). Quintana Roo: Municipio Benito Juárez. $2 \mathrm{~km}$ al sur de Puerto Morelos, en la brecha a Vallarta, 11 Ene 1981, Cabrera y Torres 8710 (MO). Municipio Cozumel. Isla Cozumel, 7 Ago 1981, Flores \& Ucán 8927 (CICY, XAL); S de Cozumel, rumbo al Cedral, 29 Ago 1985, Ortiz 933 (MEXU, MO). (Fig. 2C).

Paspalum plicatulum Michx., Fl. Bor.-Amer. 1: 45. 1803. TIPO: ESTADOS UNIDOS DE AMÉRICA. Hab. in Georgia, Florida, A. Michaux s.n. (holotipo, P-MICH; isotipo, US-2942519) (Fig. 1O).

Ic. Allen, C. M y D. W. Hall. 2003. Paspalum L. In: Flora of North America Editorial Committee, eds. 1993+. Flora of North America North of Mexico 16+ vols. New York and Oxford. Vol. 25(2): 583.

Perennes, cespitosas. Culmos erectos, ramificados, 50-100 $\mathrm{cm}$ alto; entrenudos y nudos glabros. Hojas con vainas comprimidas longitudinalmente, glabras a pelosas; lígula 1.5-2 mm largo; láminas $35 \mathrm{~cm}$ largo, 2-10 mm ancho, lineares, plegadas cerca de la base, por lo demás aplanadas, glabras a pilosas, los márgenes glabrescentes. Sinflorescencia 6-14 cm largo con 4-7 racimos 3-8 cm largo, patentes, laxos; raquis 0.5-1.1 mm de ancho, angostamente alado, en zigzag, escabriúsculo marginalmente, con una espiguilla en el ápice, triquetro. Espiguillas 2.3-3 mm largo, 1.3-1.8 mm ancho, elíptico-obovadas, pareadas, en 4 filas; gluma inferior ausente; gluma superior escasamente más corta que la espiguilla, la gluma adpreso pelosa, raramente glabra, obtusa, no apiculada, con 5-7 nervios; lema inferior tan larga como la espiguilla, adpreso pelosa o glabra, corrugada transversalmente hacia los márgenes, obtusa, con 5 nervios. Flósculo superior 2.5-2.8 mm largo, estriado longitudinalmente, pardo obscuro, brillante.

Esta especie florece de julio a octubre. Es común en sabanas y áreas perturbadas, entre los 8-80 m de altitud. Paspalum plicatulum es dominante en las sabanas de la región y se asocia con otras gramíneas como P. coryphaeum Trin., P. arundinaceum Poir., Sorghastrum setosum (Griseb.) Hitchc. y ciperáceas como Scleria 
eggersiana Boeckeler y Cyperus articulatus L. En el área de estudio se registra en los tres estados. En México se conoce en Aguascalientes, Chiapas, Chihuahua, Colima, Durango, Guerrero, Guanajuato, Hidalgo, Jalisco, México, Michoacán, Morelos, Nayarit, Oaxaca, Puebla, San Luis Potosí, Sinaloa, Tabasco, Tamaulipas, Veracruz y Zacatecas. Ha sido citada como naturalizada en África Tropical, Asia y Australia. Se extiende desde Estados Unidos de América (Alabama, Carolina del Sur, Florida, Georgia, Louisiana, Mississippi, Texas), México, Mesoamérica (Belice, Guatemala, Honduras, Nicaragua, Panamá, Costa Rica y El Salvador), Sudamérica (Argentina, Bolivia, Brasil, Colombia, Guyanas, Perú, Paraguay, Surinam, Uruguay, Venezuela) hasta las Antillas (Bermudas, Islas Barlovento, Cuba, República Dominicana, Haití, Jamaica, Puerto Rico, Trinidad y Tobago).

Ejemplares examinados: Campeche: Municipio Campeche. Ejido Alfredo B. Bonfil, predio Sabana, 18 Sep 1981, Cortés 103 (CICY); carretera China - Campeche, Escuela Técnica Agropecuaria, 20 Sep 1983, Ortiz 372 (CICY, XAL); carretera Edzná - Haltunchen, división Hool y Edzná, 7 Oct 1983, Ortiz 395 (CICY, XAL). Municipio Champotón. Revolución, entre Escárcega y Champotón, 16 Nov 2012, Gutiérrez 8058 (UCAM). Municipio Hopelchén. Carretera Dzibalchén - Pich, Ejido San Miguel Allende, 27 Ago 2002, Ortiz 2133 (CICY). Municipio Palizada. Carretera rumbo a Palizada, km 7, 10 Abr 1985, Ortiz 792 (CICY, XAL). Municipio Tenabo. Ejido Emiliano Zapata, 26 Sep 1984, Ortiz 609 (CICY, XAL). Quintana Roo: Municipio Othón P. Blanco. Othón P. Blanco, 7 May 1982, Davidse et al. 20139 (MO). Yucatán: Municipio Tekax. Carretera Nohalal - Huntochac, $\mathrm{km} 4.5$ al SE sobre la carretera que cruza la sabana Nohochchakan, 7 Sep 2002, Ortiz 2154 (CICY) (Fig. 2C).

Paspalum repens P. J. Bergius, Acta Helv. Phys.-Math. 7: 129, t. 7.1762 (1772). TIPO: SURINAM. Sin localidad, sin colector (holotipo, SBT) (Fig. 1P).

Ic. Allen, C. M y D. W. Hall. 2003. Paspalum L. In: Flora of North America Editorial Committee, eds. 1993+. Flora of North America North of Mexico 16+ vols. New York and Oxford. Vol. 25(2): 573.

Perennes, acuáticas. Culmos largamente rastreros, flotantes, enraizando, 120-200 cm alto; entrenudos y nudos glabros. Hojas con vainas infladas, glabras o papiloso-pilosas; lígula 2.5-3 mm; láminas 20-30 cm largo, 6-14 mm ancho, anchamente lineares a lanceoladas, aplanadas, laxamente pelosas o escabrosas, márgenes ciliados hacia la base. Sinflorescencia 9-16 cm de largo; 20-40 racimos de 4-7 cm largo, ascendentes a patentes, laxos, deciduos, enteros en la madurez; raquis 1.5-2 $\mathrm{mm}$ de ancho, escabroso, sin o con espiguilla en el ápice, excurrente, alado, las alas 
herbáceas. Espiguillas 1.8-2 mm largo, $0.8 \mathrm{~mm}$ ancho, elípticas, solitarias, en 2 filas; gluma inferior ausente; gluma superior y lema inferior tan largas como la espiguilla, hialinas, glabras o puberulentas, agudas, con 2-3 nervios. Flósculo superior 1.5-1.7 mm largo, liso, blanquecino.

Esta especie florece de junio a agosto. Se localiza en lugares de suelo húmedo y aguas estancadas a nivel del mar. En el territorio estudiado se la conoce de Campeche, y en México solo se sabe además de su existencia en los estados de Chiapas, Tabasco y Veracruz. A nivel general, esta especie se ha registrado en Asia, Estados Unidos de América (Alabama, Arkansas, Carolina del Norte, Carolina del Sur, Florida, Georgia, Illinois, Indiana, Kentucky, Luisiana, Maryland, Misisipi, Misuri, Ohio, Oklahoma, Tennessee, Texas, Virginia), México, Mesoamérica (Belice, Costa Rica, Guatemala, Honduras, Nicaragua, Panamá, El Salvador), Sudamérica (Argentina, Bolivia, Brasil, Colombia, Ecuador, Guyanas, Paraguay, Perú, Surinam, Uruguay, Venezuela) y las Antillas (Cuba, Jamaica, Trinidad y Tobago).

Ejemplar examinado: Campeche: Municipio Palizada. Palizada, 1980, Bazaldúa s.n. (MEXU) (Fig. 2D).

Paspalum sparsum Chase, Publ. Carnegie Inst. Wash. 436: 341, f. 5. 1934. TIPO: MÉXICO. Yucatán, along road through brush, Uxmal, 20-21 Jul 1932, J. R. Swallen 2633 (holotipo, US-1537442) (Fig. 1Q).

Ic. Swallen, J. R., The grasses of the Yucatan Peninsula. Publ. Carnegie Inst. Wash. 436: 341. 1934.

Perennes, cespitosas. Culmos erectos, simples, 50-108 cm alto; entrenudos más o menos pilosos; nudos superiores pilosos. Hojas con vainas comprimidas longitudinalmente, papiloso-pilosas, el cuello densamente piloso; lígula de $0.5 \mathrm{~mm}$ largo; láminas 12-30 cm largo, 5-12 mm ancho, lineares, aplanadas, sedoso-pelosas, márgenes glabrescentes. Sinflorescencia $17 \mathrm{~cm}$ largo con 8 racimos de $2-9.5 \mathrm{~cm}$ largo, patentes, laxos; raquis $0.8 \mathrm{~mm}$ de ancho, glabro, con una espiguilla en el ápice, triquetro. Espiguillas 1.4-1.5 mm largo, $1 \mathrm{~mm}$ ancho, obovadas, pareadas, en 4 filas; gluma inferior ausente; gluma superior y lema inferior tan largas como las espiguillas, lanosas, obtusas, con 3-5-nervios. Flósculo superior $1 \mathrm{~mm}$ largo, liso, amarillo pálido.

Esta planta florece en julio y agosto. Crece en áreas abiertas de la selva baja caducifolia, entre 18 y $70 \mathrm{~m}$ de altitud. Es una especie endémica de la Península de Yucatán localizada en los estados de Campeche y Yucatán. 
Ejemplares examinados: Campeche: Municipio Champotón. Camino HoolArellano, 3 Nov 1981, Ortiz 156 (CICY, XAL). Yucatán: Municipio Santa Elena. Santa, 20-21 Jul 1932, Swallen 2633 (MEXU, US) (Fig. 2D).

Paspalum vaginatum Sw., Prodr. 21. 1788. TIPO: JAMAICA. Sin localidad, O. P. Swartz s.n. (holotipo S; isotipo US-80042) (Fig. 1R).

Ic. Allen, C. M y D. W. Hall. 2003. Paspalum L. In: Flora of North America Editorial Committee, eds. 1993+. Flora of North America North of Mexico 16+ vols. New York and Oxford. Vol. 25(2): 576.

Perennes, rizomatosas y estoloníferas. Culmos erectos, ramificados, 40-50 cm alto; entrenudos y nudos glabros. Hojas con vainas comprimidas longitudinalmente, glabras salvo pelos auriculares prominentes; lígula 0.5-1 mm largo; láminas 3-7 cm largo, 1-4 mm ancho, lineares, rígidas, aplanadas a involutas, glabras o esparcidamente ciliadas, márgenes glabros. Sinflorescencia 3-7 cm largo; con 2(-4) racimos de 3-7 cm largo, conjugados, cuando 2, éstos divergentes, laxos; raquis 1-2.5 $\mathrm{mm}$ de ancho, glabrescentes, con una espiguilla en el ápice, aplanado. Espiguillas 3.2-4 mm largo, 1.2-1.5 mm ancho, elíptico-ovadas a obovadas, solitarias, en 2 filas; gluma inferior ausente; gluma superior y lema inferior tan largas como la espiguilla, glabras, agudas, con (4)5 nervios. Flósculo superior 2.5-3 mm largo, diminutamente estriado, blanquecino.

Esta especie florece de junio a octubre. Se encuentra en sabanas costeras de suelos salobres, entre los 2-50 m de altitud y se asocia generalmente a Spartina spartinae (Trin.) Merr. ex Hitchc. y Distichlis spicata (L.) Greene. En el área de estudio se encuentra en Campeche, Quintana Roo y Yucatán. En México se encuentra además en Baja California Sur, Chiapas, Guanajuato, Colima, Jalisco, México, Michoacán, Nayarit, Oaxaca, Puebla, Querétaro, San Luis Potosí, Tabasco, Tamaulipas, Veracruz y Zacatecas. A nivel global esta especie tiene distribución cosmopolita.

Ejemplares examinados: Campeche: Municipio Calkiní. El Remate, 13 Oct 2000, Ortiz 2081 (UADY). Municipio Campeche. $1 \mathrm{~km}$ al S de Campeche, 2 Sep 1958, Sauer 2410 (WIS); Playa Bonita, cerca de Punta Morros, 4 km al S de Lerma, 3 Sep 1958, Sauer 2428 (WIS); carretera Edzná - Haltunchén, entre Arellano y Sihochac, 27 Sep 1984, Ortiz 666 (CICY, XAL). Quintana Roo: Municipio Benito Juárez. Noreste de Ciudad Cancún, 9 Jul 1992, Ucán et al. 8561 (UADY). Municipio Tulum. Zona arqueológica de Cobá, Ortiz 515 (CICY, UADY). Yucatán: Municipio 
Progreso. Laguna de Progreso, $2 \mathrm{~km}$ al S de Progreso, 26 Sep 1968, Gould 12600 (MO); El Progreso, 28 Oct 1984, G. Davidse y Davidse 29453 (MO) (Fig. 2D).

Paspalum virgatum L., Syst. Nat. ed. 10, 2: 855. 1759. TIPO (lectotipo designado por Hitchcock, Contr. U.S. Natl. Herb. 12: 116. 1908): JAMAICA. Sin localidad, P. Brown s.n., LINN-80.26 (Fig. 1S).

Ic. Allen, C. M y D. W. Hall. 2003. Paspalum L. In: Flora of North America Editorial Committee, eds. 1993+. Flora of North America North of Mexico 16+ vols. New York and Oxford. Vol. 25(2): 582.

Perennes, cespitosas. Culmos erectos, simples, $60-200 \mathrm{~cm}$ alto, generalmente más de $100 \mathrm{~cm}$; entrenudos y nudos glabros. Hojas con vainas redondeadas o comprimidas longitudinalmente, glabras, ciliadas; lígula de 2-3 mm largo; láminas hasta 30-65 cm largo, 12-26 mm ancho, lineares, aplanadas, glabras o puberulentas, márgenes glabrescentes. Sinflorescencia 10-20 cm largo, con 6-13 racimos de 6-14 cm largo, ascendentes a patentes o nutantes, laxos; raquis 1-1.5 mm de ancho, angosto, escabroso y esparcidamente ciliado, con una espiguilla en el ápice, triquetro. Espiguillas 2.8-3.2 mm largo, 1.6-2 mm ancho, obovadas, pareadas, en 4 filas; gluma inferior ausente; gluma superior y lema inferior tan largas como la espiguilla, puberulentas, obtusas, no apiculadas, con 5 nervios. Flósculo superior 2.5-3 mm largo, papiloso-estriado, pardo.

Esta especie florece de mayo a octubre. Habita en áreas abiertas de suelo húmedo en sabanas, selva baja inundable y selva mediana subcaducifolia. Se encuentra entre los 7-260 m de altitud. En la Península se ha recolectado en los tres estados. En México además se encuentra en Chiapas, Colima, Guerrero, Jalisco, México, Michoacán, Morelos, Nayarit, Oaxaca, Puebla, San Luis Potosí, Tabasco, Tamaulipas, Veracruz y Yucatán. Ha sido registrada en África tropical y en el sudeste de Asia. Su distribución en este continente abarca Estados Unidos de América (Alabama, Georgia, Texas), México, Mesoamérica (Belice, Guatemala, Honduras, El Salvador, Nicaragua, Costa Rica y Panamá), Sudamérica (Argentina, Bolivia, Brasil, Colombia, Ecuador, Guyanas, Paraguay, Perú, Surinam, Venezuela) y las Antillas (Islas Barlovento, Cuba, República Dominicana, Haití, Jamaica, Puerto Rico, Trinidad y Tobago).

Ejemplares examinados: Campeche: Municipio Calakmul. Mina de Yeso Coconal, a 23 km al O de Xpujil, camino a Escárcega, 11 Ago 1997, Martínez et al. 28415 (MEXU); a 3 km al SE de Dos Naciones, camino a El Civalito, 6 Ago 1997, 
Martínez et al. 28129 (MEXU); a 10 km al SE de Ley de Fomento Agropecuario, camino a Dos Naciones, 23 Oct 1997, Martínez et al. 29174 (MO); Narciso Mendoza, 26 Jun 1997, Álvarez 28 (MO); a 8 km al E de Ucum, camino a Dzibalchén, 10 Oct 1997, Martínez et al. 28596 (MEXU); a 13 km al S de Xcan-ha, camino a Xpujil, 11 Oct 1997, Martínez et al. 28726 (CICY); Zoh-Laguna, 7 Abr 1983, Chan 2073 (CICY, XAL). Municipio Campeche. 2 km N Chiná, 27 Sep 1998, Gutiérrez 5965 (CICY); carretera Edzná - Haltunchén, entronque a la estación del FFCC de Hool, 7 Oct 1983, Ortiz 392 (CICY, UADY); de Escárcega hacia Tabasco, 23 Oct 1982, Flores et al. 9594 (CICY). Municipio Candelaria. $2 \mathrm{~km}$ al E de La Misteriosa, 2 Ago 2002, Gutiérrez 7500 (CICY, UCAM). Municipio Hopelchén. 21 km al S de Pakchén por la vía Hopelchén - Xpujil, 20 Sep 1999, Carnevali et al. 5713 (CICY). Municipio Palizada. Carretera rumbo a Palizada, km 7, 10 Abr 1985, Ortiz y Herrera 791 (CICY, XAL). Quintana Roo: Municipio Felipe Carrillo Puerto. Laguna Muyil, 1 km E of ruinas Chunyaxche, 19 May 1982, Davidse et al. 20637 (MEXU, MO). Municipio José María Morelos. $3 \mathrm{~km}$ al N de San José de la Montaña, en la carretera a Garrido, 9 May 1982, Davidse et al. 20247 (MEXU, MO). Municipio Othón P. Blanco. Bahía de Chetumal, 17 Nov 1980, Calzada et al. 7034 (CICY, XAL); km 20 carretera Chetumal - Escárcega, 20 Jul 1983, Chan 2583 (CICY, XAL); a 12 km al S del Ingenio Álvaro Obregón, 11 Abr 1980, Téllez y Cabrera 1992 (CICY); carretera El Palmar - La Unión, km 46, 14 May 1985, Ortiz 842 (CICY). Municipio Tulum. Zona arqueológica de Cobá, 30 Jun 1984, Ortiz 513 (CICY, MO, XAL). Yucatán: Municipio Tekax. Nohalal, Ortiz y Magaña 2180 (CICY, UADY) (Fig. 2D).

Paspalum wrightii Hitchc. \& Chase, Contr. U.S. Natl. Herb. 18(7): 310. 1917. TIPO: CUBA. Pinar del Rio, C. Wright 3843 (holotipo, US-865562; isotipo: NY71046 (fragm.)) (Fig. 1T).

Ic. Allen, C. M y D. W. Hall. 2003. Paspalum L. In: Flora of North America Editorial Committee, eds. 1993+. Flora of North America North of Mexico 16+ vols. New York and Oxford. Vol. 25(2): 585.

Perennes, semiacuáticas, rizomatozas o estoloníferas. Culmos erectos, esparcidamente ramificados desde los nudos superiores, $120-150 \mathrm{~cm}$ alto; entrenudos y nudos glabros. Hojas con vainas redondeadas, glabras o el cuello piloso; lígula 1-1.3 mm largo; láminas de 30-45 cm largo, 3-6 mm ancho, lineares, aplanadas pero involutas hacia el ápice, escabrosas en el envés, esparcidamente pilosas en el haz, márgenes glabrescentes. Sinflorescencia hasta de $20 \mathrm{~cm}$ largo con 4-5 racimos de 6-8 cm largo, ascendentes, laxos; raquis 1-1.5 mm de ancho, angosto, glabro, con 
una espiguilla en el ápice, triquetro. Espiguillas 2.5-2.8 mm largo y 1-1.1 mm ancho, elípticas o elíptico-obovadas, pareadas, en 4 filas; gluma inferior ausente; gluma superior y lema inferior tan larga como la espiguilla, glabras, subagudas, gluma superior con 3-5 nervios, lema inferior irregularmente rugosa, con 3 nervios. Flósculo superior 2-2.2 mm largo, liso, pardo brillante.

Esta especie florece de julio a septiembre. Se encuentra en zonas inundables, en petenes y la selva baja inundable cercana a nivel del mar. En México se conoce de Campeche y ha sido citada para Yucatán y Tabasco (Sánchez-Ken, 2010). Presenta una distribución general que abarca los Estados Unidos de América de América (Louisiana, Texas), México, Sudamérica (Argentina, Bolivia, Brasil, Colombia, Guyana, Paraguay, Uruguay, Venezuela) y las Antillas (Cuba).

Ejemplar examinado: Campeche: Municipio Calkiní. Carretera Tankuché El Remate, entre San Nicolás y Tankuché, 22 Sep 2003, Ortiz 2241 (CICY). Municipio Campeche. Alrededores de Chiná a aprox. $10 \mathrm{~km}$ al sureste de la Ciudad de Campeche, 1 Nov 1980, Novelo y Cetina 731 (MO) (Fig. 2D).

Paspalum subg. Anachyris Chase, Contr. U.S. Natl. Herb. 24: 435. 1927. TIPO: Paspalum malacophyllum Trin.

= Anachyris Nees, Hooker's J. Bot. Kew Gard. Misc. 2: 103. 1850. TIPO: A. paspaloides Nees.

$\equiv$ Paspalum subsect. Anachyris (Nees) Benth., J. Linn. Soc., Bot. 19: 36. 1881; Benth. \& Hook., Gen. Pl. 3: 1097. 1883.

$\equiv$ Paspalum sect. Anachyris (Nees) Pilger, Repert. Spec. Nov. Regni Veg. 26: 229.1929.

三 Paspalum grupo Malacophylla Chase, Contr. U.S. Natl. Herb. 28: 228. 1929.

Plantas perennes, rizomatosas o estoloníferas. Culmos erguidos o geniculados. Sinflorescencias terminales y axilares, multiracemosas. Espiguillas naviculares, glabras; glumas ausentes, ocasionalmente presentes; lema superior sulcada por 5 nervios prominentes. Flósculo superior coriáceo, con papilas simples.

Paspalum malacophyllum Trin., Sp. Gram. 3(23): f. 271. 1836. TIPO: BRASIL. Cuiabá, Chapada, 1829, G. H. von Langsdorff s.n. (holotipo, LE; isotipos, K, LE, SI, US-2764383) (Fig. 1U).

= Anachyris setaria E. Fourn., Mexic. Pl. 2: 2. 1886. TIPO: MÉXICO. San Luis Potosí (P. T. Virlet 1327) (holotipo, P; isotipo, US-76422).

Ic. Morrone, O. et al., Candollea 55: 116. 2000. 
Perennes, cespitosas, en ocasiones con rizomas cortos. Culmos erectos, ramificados, $100-150 \mathrm{~cm}$ alto; entrenudos y nudos glabros. Hojas con vainas no comprimidas, papiloso-pilosas; lígula 1-1.5 mm largo; láminas 35-40 cm largo, 8-15 $\mathrm{mm}$ ancho, anchamente lineares, aplanadas, glabras o pilosas. Sinflorescencia 10-25 cm largo, con 15-30 racimos de 6-12 cm largo, ascendentes, laxos; raquis 0.8-1.5 mm ancho, escabroso, esparcidamente ciliado, con espiguilla en el ápice, aplanado. Espiguillas 1.8-2 mm largo y $1 \mathrm{~mm}$ ancho, oblongo-elípticas, pareadas, en 4 filas; glumas ausentes; lema superior coriácea, glabrescente, sulcada entre las nervaduras, marcadamente cóncava, obtusa, con 5 nervios marcados; lema inferior tan larga como la espiguilla, membranácea, glabrescente, con 3 nervios. Flósculo superior $2 \mathrm{~mm}$ largo, longitudinalmente papiloso-estriado, amarillo pálido.

Esta especie florece de julio a septiembre. Habita en pastizales de áreas abiertas en selva mediana subcaducifolia, entre los 2-60 m de altitud. En el área de estudio se localiza en los estados de Quintana Roo y Yucatán. En México se conoce además de Chiapas, Querétaro, San Luis Potosí, Tabasco, Tamaulipas y Veracruz. A nivel mundial esta especie ha sido introducida en Asia y Estados Unidos de América (Florida, Georgia, Hawai, Texas). Su área de distribución abarca México, Sudamérica (Argentina, Bolivia, Brasil, Paraguay) y las Antillas (Puerto Rico).

Ejemplares examinados: Quintana Roo: Municipio Tulum. Cobá, Jun-Jul 1938, Lundell y Lundell 7838 (MO). Yucatán: Municipio Santa Elena. Uxmal, MayAgo 1938, Lundell y Lundell 8168 (MO). Municipio Tinum. Chichen Itzá, 7-13 Jul 1932, Swallen 2419 (MO) (Fig. 2D).

Paspalum subg. Harpostachys (Trin.) S. Denham, Ann. Missouri Bot. Gard. 92(4): 475. 2005. TIPO: Paspalum decumbens Sw. [ $\equiv$ Panicum decumbens (Sw.) Roem. \& Schult. (lectotipo designado por Denham, Ann. Missouri Bot. Gard. 92: 463-532. 2005)].

$\equiv$ Panicum sect. Harpostachys Trin., Mém. Acad. Imp. Sci. Saint-Petersbourg, Math., Seconde Pt. Sci. Nat. 3(2): 194, 227. 1834.

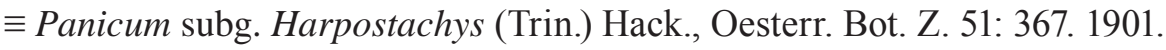

= Thrasya Kunth., Nov. Gen. Sp. 1: 120-121. 1815. (1816). TIPO: T. paspaloides Kunth.

三 Panicum sect. Thrasya (Kunth.) Benth., J. Linn. Soc. Bot. 18: 42. 1881.

= Dimorphostachys E. Fourn., Compt. Rend. Acad. Sci. Paris 80: 441. 1875. TIPO:

D. monostachya (Kunth) E. Fournet. 
= Tylothrasya Döll, Fl. Bras. 2: 295. 1877. TIPO: Tylothrasia petrosa (Trin.) Doll. [=Paspalum foliiforme S. Denham. TIPO: BRASIL. M. Cuyaba, Feb. 1827, G. H. von Langsdorff s.n. (holotipo, LE-TRIN-0833.01)].

三 Paspalum grupo Decumbentes Chase, Contr. U.S. Natl. Herb. 28: 91. 1929.

Plantas perennes, raramente anuales, cespitosas. Culmo erecto a decumbente. Sinflorescencias terminales y axilares en la vaina foliar apical, racimos solitarios. Espiguillas plano-convexas o cóncavo-convexas, no naviculares, glabras, puberulentas o pelosas; gluma inferior usualmente presente y dimorfa en las espiguillas del par; gluma superior usualmente presente; pálea inferior reducida o ausente, usualmente hialina salvo los nervios endurecidos; lema superior lisa, con nervios indistinguibles. Flósculo superior crustáceo a membranáceo, con papilas verrugosas, menos frecuentemente con papilas simples o con la superficie lisa.

Paspalum botterii (E. Fourn.) Chase, J. Wash. Acad. Sci. 13(20): 436. 1923. (Fig. 1V). $\equiv$ Dimorphostachys botterii E. Fourn., Mexic. Pl. 2: 14. 1886. TIPO: MÉXICO. Orizaba, M. Botteri 118 (holotipo, P00741004).

= Dimorphostachys langei E. Fourn., Mexic. P1. 2: 14. $1886 \equiv$ Paspalum langei (E. Fourn.) Nash, N. Amer. Fl. 17: 179. 1912. TIPO (lectotipo designado por Chase, Contr. U.S. Natl. Herb. 28: 105. 1929): MÉXICO. Mecapalco, F. M. Liebmann 179, en parte C; isotipo, US-80067.

= Dimorphostachys paspaloides E. Fourn., Mexic. Pl. 2: 14. 1886. TIPO (lectotipo designado por Chase, Contr. U.S. Natl. Herb. 28: 110. 1929): MÉXICO. Veracruz, L. T. Gouin 32, P; isotipo, US-865863.

= Paspalum abbreviatum Trin. ex E. Fourn., Mexic. Pl. 2: 10. 1886. TIPO: MÉXICO. Veracruz, C. J. W. Schiede 888 (holotipo, LE; isotipo, US-951532).

= Paspalum macrophyllum var. piliferum E. Fourn., Mexic. Pl. 2: 1. 1886. SINTIPOS: MÉXICO, Orizaba, M. Botteri 117, julio (BM, B, P, US-906996); Consoquitla, F. M. Liebmann 117, agosto (P); Santa María Tlatella, F. M. Liebmann 168, junio 1841 (P; isotipo: C, US-906995).

= Paspalum lineare E. Fourn., Mexic. Pl. 2: |12. 1886. non Paspalum lineare Trin., Gram. Panic. 99: 1826. TIPO (lectotipo designado por Chase, Contr. U.S. Natl. Herb. 28: 104. 1929): MÉXICO, F. M. Liebmann 192, C; isotipo, US-80067).

= Paspalum varians A. Rich. ex E. Fourn., Mexic. Pl. 2: 11. 1886, nom. nud.

= Paspalum palmeri Chase, Contr. U.S. Natl. Herb. 28(1): 109. 1929. Nombre reemplazado: Paspalum setaceum Michx. var. pubiflorum Vasey, Contr. U.S. Natl. Herb. 
1: 114. 1891. TIPO: MÉXICO. Sonora, E. Palmer 704 (holotipo, US-951577; isotipo, W, US-824351, US-824352, US-1060374).

Ic. Pohl, R. W., Flora Costaricensis. Fieldiana, Bot. 4(15): 406, Fig. 147. 1980.

Perennes cespitosas, base nodulosa. Culmos ascendentes, simples, $70-100 \mathrm{~cm}$ alto; entrenudos glabros; nudos glabros o adpreso-pilosos. Hojas con vainas comprimidas lateralmente, más o menos papiloso-híspidas, ciliadas, collar piloso; lígula 1-1.5 mm largo; láminas hasta 6-32 cm largo, 8-22 mm ancho, lineares a lanceoladas, aplanadas, glabras o papiloso-pilosas, márgenes escabrosos. Sinflorescencia 12-26 cm largo con 2-5 racimos de 5-18 cm largo, raramente 1-2 axilares, ascendentes o divergentes, laxos; raquis 0.5-1 mm de ancho, angosto, esparcidamente ciliado o glabro, con una espiguilla en el ápice, más menos aplanado. Espiguillas 2-3 mm largo, 1.3-1.4 mm ancho, elípticas o elíptico-obovadas, pareadas, en 4 filas; gluma inferior usualmente presente y dimorfa en las espiguillas de un par, en la espiguilla primaria 0.3-0.5 mm largo, ciliada, deltoide, en la espiguilla secundaria, 0.4-1.5 mm largo, aguda, angostamente triangular, 1-nervia; gluma superior ligeramente más corta o igual que la espiguilla, glabra, puberulenta o pelosa, con manchas glandulares, subaguda, no apiculada, con 3-5 nervios; lema inferior glabra o esparcidamente puberulenta, aguda, con manchas glandulares dispersas o sin ellas, con 3-5 nervios; palea inferior reducida o ausente. Flósculo superior 2.2-2.4 mm largo, diminutamente papiloso-estriado, blanquecino.

Esta especie florece de julio a octubre. Se encuentra en bordes de caminos en selva baja-mediana subperennifolia y subcaducifolia, entre los 4-400 m de altitud. En el territorio de estudio se la conoce de los tres estados. En México además se ha registrado su presencia en Chihuahua, Chiapas, Colima, Guerrero, Hidalgo, Jalisco, Michoacán, Morelos, Nayarit, Nuevo León, Oaxaca, Puebla, Querétaro, San Luis Potosí, Sinaloa, Sonora, Tabasco, Tamaulipas y Veracruz. Se distribuye de Estados Unidos de América (Luisiana, Florida, Oklahoma, Texas), México, Mesoamérica (Belice, Costa Rica, Guatemala, Honduras, Nicaragua, El Salvador) a Sudamérica (Brasil, Colombia, Venezuela) y las Antillas (Cuba, República Dominicana, Haití).

Ejemplares examinados: Campeche: Municipio Calakmul. A $500 \mathrm{~m}$ al N del poblado, 14 Oct 1997, Madrid et al. 125 (MEXU, MO); a $20 \mathrm{~km}$ al S de la caseta de vigilancia de la Reserva de la Biosfera de Calakmul, 24 Nov 1997, Lira et al. 445, 462 (MEXU, MO); a $6 \mathrm{~km}$ al S de la entrada a Calakmul, 16 Oct 1997, Martínez et al. 28876 (MEXU); a $10 \mathrm{~km}$ al SE de Ley de Fomento Agropecuario, camino a Dos Naciones, 23 Oct 1997, Martínez et al. 29167 (MEXU); La Aguada, a 2 km al O de 
Calakmul, 17 Oct 1997, Martínez et al. 28976 (MEXU); a 0.8 km al E de La Moza, 13 Ago 2002, Álvarez 1760 (UCAM); a 4 km al SE de La Nueva Vida, 2 Ago 1997, Martínez et al. 27936 (MEXU), 2 Ago 1997, Martínez et al. 27938 (MEXU, MO); a $2 \mathrm{~km}$ al O de Plan de San Luis, en el km 132 de la carretera Escárcega - Chetumal, 26 Nov 1997, Madrid et al. 589 (MO); a 16 km al NE de Zoh-Laguna, 4 Ago 1997, Martínez et al. 28045 (MEXU). Municipio Campeche. Chiná, 10 Oct 2008, Carvajal 7 (UADY). Carretera Edzná - Cayal, km 7, 26 Sep 1984, Ortiz 627 (CICY, XAL); al S de Ejido Libertad, 7 Nov 1984, Ortiz 716 (CICY, XAL); 4 km del camino a Uayamón, 20 Sep 1983, Ortiz 365 (CICY, XAL). Municipio Candelaria. Ejido el Naranjo, Rancho La Lucha, 17 Feb 1983, Ortiz s.n. (CICY). Municipio Champotón. Tuxpeña, 18 Nov 1931, Lundell 951 (MO, WIS). Municipio Escárcega. O de Escárcega, 21 Dic 1972, Reeder y Reeder 6095 (MO). Municipio Tenabo. Hacienda Chilip, 29 Nov 1997, Zamora y Uc 5947 (CICY). Quintana Roo: Municipio Carmen. Carretera Puerto Real - Ciudad del Carmen, a $10 \mathrm{~km}$ de la ciudad, 8 Nov 1984, Ortiz 731 (CICY, XAL). Municipio José María Morelos. San José de la Montaña, 9 May 1982, Davidse et al. 20273(MEXU, MO). Municipio Lázaro Cárdenas. Ejido Benito Juárez, 1 Ago 1982, Ortiz 212 (CICY); ejido Vicente Guerrero, 7 Ago 1982, Ortiz 218 (CICY). Municipio Othón P. Blanco. Predio Pablo Caballero, ejido Juan Sarabia, 20 Oct 1982, Ortiz s.n. (CICY, UADY). Municipio Solidaridad. Carretera Nuevo X - Can Cobá, 30 Jun 1984, Ortiz 505 (CICY, XAL). Yucatán: Municipio Opichén. Carretera Muna - Opichén, km 10, 24 Sep 1984, Ortiz 563 (CICY, XAL). Municipio Río Lagartos. A 1 km al E de la caseta de vigilancia de la reserva de Río Lagartos, $9.2 \mathrm{~km}$ al S de El Cuyo, 2 Oct 1999, Durán y Simá 3503 (CICY). Municipio Tekax. Nohalal, aguada de Nohalal, 7 Sep 2002, Ortiz 2178 (CICY, UADY). Municipio Ticul. 8 km al O de Ticul, 27 Abr 1992, Kú y Yam 171 (CICY, UADY). Municipio Valladolid. Pixoy, cerca de quinta de Gabriel Yam Koyoc, 23 Jun 1988, de Voeyer 24 (CICY, UADY); 2 km al SO de Yalcobá, 7 Jul 1984, Ortiz 533 (CICY, XAL) (Fig. 2D).

Además de las especies consideradas en este estudio, se han citado para la

Península de Yucatán Paspalum distichum L., P. nutans Lam., P. pilosum Lam. y P. pubiflorum Rupr. (Durán y Olmsted, 1987; Arellano et al., 2003; Sánchez-Ken, 2010). Sin embargo, no fue posible corroborar su presencia en el territorio estudiado.

\section{AGRADECIMIENTOS}

Los autores agradecen a todos los responsables de los herbarios e instituciones citadas por la ayuda prestada y a los revisores anónimos por los comentarios 
que enriquecieron el manuscrito. Itziar Arnelas Seco estuvo adscrita como becaria postdoctoral PROMEP (Programa de Mejoramiento del Profesorado, Secretaría de Educación Pública, Gobierno de México), y con una beca otorgada por la Secretaria de Relaciones Exteriores del Gobierno de México (ARNITZ 81031712).

\section{LITERATURA CITADA}

Arellano, R., S. Flores, J. Tun y M. M. Cruz. 2003. Nomenclatura, forma de vida, uso, manejo y distribución de las especies vegetales de la península de Yucatán. Etnoflora yucatanense. Fascículo 20. Universidad Autónoma de Yucatán. Mérida, México. 815 pp.

Allen, C. M y D. W. Hall. 2003. Paspalum L. In: Barkworth, M. E., J. M. Capels, S. Long $\&$ M. B. Piep (eds.). Flora of North America. Oxford University Press. New York, USA. pp. 566-599.

Beetle, A. A., G. Villegas, A. Bolaños, A. Miranda, L. Aragón, M. A. Vergara, A. Chimal, M. M. Castillo, O. M. Galván, J. L. Villalpando, M. Lizama, J. Valdés-Reyna, E. Manrique y A. M. Rodríguez. 1999. Las gramíneas de México. V. Secretaría de Cultura y Recursos Hidráulicos, Comisión Técnico Consultiva de Coeficientes de Agostadero. México. D.F., México. 482 pp.

Carnevali, F. C., G., J. L. Tapia-Muñoz, R. Duno de Stefano e I. Ramírez-Morillo (eds.). 2010. Flora ilustrada de la Península de Yucatán: Listado florístico. Centro de Investigación Científica de Yucatán, A. C. Mérida, México. 328 pp.

Chase, A. 1929. The North American species of Paspalum. Contr. U.S. Natl. Herb. 28(1): 1-675.

Cialdella, A. M., O. Morrone y F. O. Zuloaga. 1995. Revisión de las especies del género Paspalum (Poaceae: Panicoideae: Paniceae) grupo Bonplandiana. Darwiniana 33: 67-95.

Clayton, W. D. y S. A. Renvoize. 1986. Genera graminum. Her Majesty's Stationary Office. London, UK. 389 pp.

Dávila, P., M. T. Mejía-Saulés, M. Gómez-Sánchez, J. Valdés-Reyna, J. J. Ortiz, C. Morín, J. Castrejón y A. Ocampo. 2006. Catálogo de las gramíneas de México. Universidad Autónoma de México, Comisión Nacional para el Conocimiento y Uso de la Biodiversidad. México, D.F., México. 671 pp.

Denham, S. S. 2005. Revisión sistemática del subgénero Harpostachys de Paspalum (Poaceae: Panicoideae: Paniceae). Ann. Missouri Bot. Gard. 92: 463-532.

Denham, S. S., O. Morrone y F. O. Zuloaga. 2010. Estudios en el género Paspalum (Poaceae, Panicoideae, Paniceae): Paspalum denticulatum y especies afines. Ann. Missouri Bot. Gard. 97(1): 11-33.

Denham, S. S., F. O. Zuloaga y O. Morrone. 2002. Systematic revision and phylogeny of Paspalum subgenus Ceresia (Poaceae: Panicoideae: Paniceae). Ann. Missouri Bot. Gard. 89: 337-399. 
Döll, J. C. 1877. Graminae. Flora Brasiliensis 2(2): 1-358.

Durán, R. y I. Olmsted. 1987. Listado florístico de la reserva de Sian ka’an. Amigos de Sian ka'an. Puerto Morelos, México. 71 pp.

Hitchcock, A. S. 1971. Manual of the grasses of the United States. Vol. 2. Dover Pub. New York, USA. pp. 570-1051.

Hitchcock, A. S. 1936. Manual of the grasses of the West Indies. Miscel. Pub. 243. United States Government Printing Office. Washington, USA. 439 pp.

Morrone, O., A. S. Vega y F. O. Zuloaga. 1996. Revisión del grupo Dissecta (s. str.) del género Paspalum (Poaceae: Panicoideae: Paniceae). Candollea 51: 2-34.

Morrone, O., F. O. Zuloaga y E. Carbonó. 1995. Revisión del grupo Racemosa del género Paspalum (Poaceae: Panicoideae: Paniceae). Ann. Missouri Bot. Gard. 82: 82-116.

Morrone, O., L. Aagese, M. A. Scataglini, D. L. Salariato, S. S. Denham, M. A. Chemisquy, S. M. Sede, L. M. Giussani, E. A. Kellogg y F. O. Zuloaga. 2012. Phylogeny of the Paniceae (Poaceae: Panicoideae): integrating plastid DNA sequences and morphology into a new classification. Cladistics 28: 333-356.

Morrone, O., S. S. Denham y F. O. Zuloaga. 2004. Revisión taxonómica del género Paspalum grupo Eriantha (Poaceae, Panicoideae, Paniceae). Ann. Missouri Bot. Gard. 91: 225-246.

Morrone, O., S. S. Denham, S. S. Aliscioni, y F. O. Zuloaga. 2000. Revisión del grupo Anachyris del género Paspalum (Poaceae: Panicoideae: Paniceae). Candollea 55: 105-155.

Nash, G. V. 1912. Poaceae: tribe 5. Paniceae. North American Flora 17(2): 144-196.

Ortiz Díaz, J. J. y J. S. Flores Guido. 2008. Poaceae I: Clave de géneros y etnobotánica. Etnoflora yucatanense. Fascículo 27. Universidad Autónoma de Yucatán. Mérida, México. 51 pp.

Pilger, R. K. F. 1929. Bemerkungen zur Systematik der Gattung Paspalum L. Repert. Spec. Nov. Regni Veg. 26: 228-231.

Pohl, R. W. 1980. Gramineae. Flora Costaricensis. Fieldiana, Bot. 4(15): 1-608.

Pohl, R. W. y G. Davidse. 1994. Paspalum L. In: Davidse, G., M. Sousa S. and A. O. Chater (eds.). Flora Mesoamericana. Vol. 6: Alismataceae a Cyperaceae. Instituto Biología, Universidad Nacional Autónoma de México. México, D.F., México. pp. 335-352.

Renvoize, R. A. 1984. The grasses of Bahia. Royal Botanic Gardens Kew. Richmond, UK. 301 pp.

Renvoize, S. A. 1998. Gramíneas de Bolivia. The Royal Botanic Gardens Kew. Richmond, UK. 644 pp.

Rodríguez, H. 1992. Pectinata Chase ex Rodríguez, nueva sección en el género Paspalum L. (Gramineae). Ernstia 2: 21-23.

Rodríguez, H. 1998. El subgénero Ceresia (Pers) Reichenb., del género Paspalum L. (Gramineae) en Venezuela. Ernstia 8: 7-50.

Rua, G. H., P. R. Speranza y M. Arakaki. 2010. A phylogenetic analysis of the genus Paspalum (Poaceae) based on cpDNA and morphology. Plant Syst. Evol. 288: 227243.

Sánchez-Ken, J. G. 2010. Two new species of Paspalum (Paniceae: Panicoideae: Poaceae), a preliminary checklist of the genus in Mexico, and the identity of P. crinitum. Rev. Mex. Biodiv. 81: 629-647. 
Soreng, R. J., G. Davidse, P. M. Peterson, F. O. Zuloaga, E. J. Judziewicz, T. S. Filgueiras \& O. Morrone (eds.). 2014. Catalogue of New World Grasses (Poaceae), version octubre 2014. Missouri Botanical Garden, St. Louis, USA. Accesible en: http://www.tropicos. org/projectwebportal.aspx?pagename=Home\&projectid=10. Consultado agosto 2014.

Swallen, J. R. 1934. The grasses of the Yucatan Peninsula. Publ. Carnegie Inst. Wash. 436: 323-355.

WCSP. 2014. World Checklist of Selected Plant Families. Facilitado por Royal Botanic Gardens, Kew. Accesible en: http://apps.kew.org/wcsp/home.do. Consultado agosto 2014.

Zuloaga, F. O. 1974. El género Paspalum (Gramineae) en la provincia de Jujuy. Bol. Soc. Argent. Bot. 16: 53-65.

Zuloaga, F. O. y O. Morrone. 2003. Paspalum L. In: Zuloaga, F. O., O. Morrone, G. Davidse, T. S. Filgueiras, P. M. Peterson, R. J. Soreng y E. J. Judziewicz (eds.). Catalogue of New World grasses (Poaceae): III. Subfamilies Panicoideae, Aristoideae, Arundinoideae and Danthonioideae. Contr. U.S. Natl. Herb. 46: 443-527.

Zuloaga, F. O. y O. Morrone. 2005. Revisión de las especies de Paspalum para América del Sur austral (Argentina, Bolivia, sur del Brasil, Chile, Paraguay y Uruguay). Monogr. Syst. Bot. Missouri Bot. Gard. 102: 1-297.

Zuloaga, F. O., J. Pensiero y O. Morrone. 2004. Systematics of Paspalum grupo Notata (Poaceae-Panicoideae-Paniceae). Syst. Bot. Monogr. 71: 1-75. 